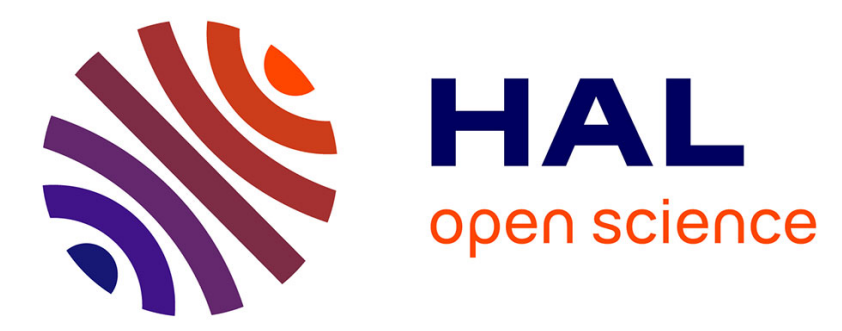

\title{
Comparison of five organic wastes regarding their behaviour during composting: Part 1, biodegradability, stabilization kinetics and temperature rise
}

A. de Guardia, P. Mallard, C. Téglia, A. Marin, C. Le Pape, M. Launay, J.C. Benoist, C. Petiot

\section{To cite this version:}

A. de Guardia, P. Mallard, C. Téglia, A. Marin, C. Le Pape, et al.. Comparison of five organic wastes regarding their behaviour during composting: Part 1, biodegradability, stabilization kinetics and temperature rise. Waste Management, 2009, 30 (3), 13 p. 10.1016/j.wasman.2009.10.019 . hal00455647

\section{HAL Id: hal-00455647 \\ https://hal.science/hal-00455647}

Submitted on 10 Feb 2010

HAL is a multi-disciplinary open access archive for the deposit and dissemination of scientific research documents, whether they are published or not. The documents may come from teaching and research institutions in France or abroad, or from public or private research centers.
L'archive ouverte pluridisciplinaire HAL, est destinée au dépôt et à la diffusion de documents scientifiques de niveau recherche, publiés ou non, émanant des établissements d'enseignement et de recherche français ou étrangers, des laboratoires publics ou privés. 


\section{COMPARISON OF FIVE ORGANIC WASTES REGARDING THEIR BEHAVIOUR DURING COMPOSTING: PART 1, BIODEGRADABILITY, STABILIZATION KINETICS AND TEMPERATURE RISE}

A. de Guardia *, P. Mallard, C. Teglia, A. Marin, C. Le Pape, M. Launay, J.C. Benoist, C. Petiot

1- Cemagref, UR GERE, 17 Avenue de Cucillé, CS 64427, F-35044 Rennes, France. 2- Université Européenne de Bretagne, F-35000 Rennes, France.

* Corresponding author. Tel. : +33223482133; Fax : +33223482115. 


\section{Abstract}

2 This paper aims to compare household waste, separated pig solids, food waste, pig slaughterhouse sludge 3 and green algae regarding their biodegradability, their stabilization kinetics and their temperature rise during composting. Three experiments in lab-scale pilots (300L) were performed for each waste, each one under a constant aeration rate. The aeration rates applied were comprised between 100 and $1100 \mathrm{~L} / \mathrm{h}$. The

6 biodegradability of waste was expressed as function of dry matter, organic matter, total carbon and chemical oxygen demand removed, on one hand, and of total oxygen consumption and carbon dioxide production on the other. These different variables were found closely correlated. Time required for stabilization of each waste was determined too. A method to calculate the duration of stabilization in case of limiting oxygen supply was proposed. Carbon and chemical oxygen demand mass balances were established and gaseous emissions as carbon dioxide and methane were given. Finally, the temperature rise was shown to be proportional to the total mass of material biodegraded during composting.

Keywords: organic waste, composting, biodegradability, stabilization rate, temperature rise, methane emissions. 


\section{Introduction}

Most of the engineering research on composting treatments aims to identify how the waste characteristics and the composting conditions influence both the composts quality and the environmental impacts of composting. Recently, research progress led the researchers to consider the active phase of composting according to its main ruling processes i.e. biological activity and heat and mass transfers. Taking into account the different natures of waste, this progress led to identify intrinsic properties, which characterize the waste regarding a specific behaviour. Then, the determination and the quantification of these properties allowed to improve mixture formulations and to adjust composting conditions.

The questions of biodegradability and stabilization illustrate the evolution described above. At first, most studies aimed to test the relevancy of numerous indicators in order to predict compost stability. Many papers dealt with the differentiation between maturity and stability, maturity being related to the presence or absence of phytotoxins whereas stability was related to microbial respiration activity of compost (Komilis and Tziouvaras, 2009). Thus, respirometric methods, based on the measurement of oxygen consumption or carbon dioxide production rate, developed. Then, in order to predict wastes behaviour in composting and adjust treatment conditions, researchers also interested to the biodegradability of the organic wastes. Taking into account the higher oxygen demand of wastes compared to the one of composts, static respirometric methods were shown to underestimate oxygen required for stabilisation (Gea et al., 2004). Nowadays, most of the authors dealing with the biodegradability of organic waste use a dynamic respirometric method i.e. with a continuous aeration (Barrena Gomez et al., 2006). However, as underlined by Berthe et al. (2007), the dynamic methods (Adani et al., 2004, Scaglia et al., 2000, Tremier et al., 2005) still differ to each other regarding the control of temperature, moisture and oxygen supply. Thus, Tremier et al. (2005) and Berthe et al. (2007) control the temperature, the moisture and the oxygen supply at the same time. In contrast, Scaglia et al. (2000) and Adani et al. (2004) simulate a composting treatment in which the temperature increase results from the material self-heating. Although temperature profile in composting simulation seems more realistic than in a thermostated bath, composting simulation does not optimise air distribution leading to a non-homogeneous aeration of the composting material. These methods also differ regarding the indicator used to characterize the biodegradability. Berthe et al. (2007), de Guardia et al. (2008) and Tremier et al. (2005) used the cumulated amount of oxygen consumed during biodegradation, whereas Adani et al. (2004) and Scaglia et al. (2000) used the maximum oxygen uptake rate measured for a short period around the maximum of biological activity. Concerning 
stabilization, the respiratory quotient i.e. the ratio of carbon dioxide production to oxygen consumption was

2 investigated as a potential indicator of stabilisation. The respiratory quotient was assumed to depend on biochemical composition of organic material. Its variation was studied by Nakasaki et al. (1985) and it was proposed to be used to control the composting process (Atkinson et al., 1997). Others found its variation was low which impedes such use (Gea et al., 2004). Adani et al. (2004) and Scaglia et al. (2000) proposed a Dynamic Respirometric Indice and considered that compost exhibited a high level of stability when DRI was lower than $500 \mathrm{mg} \mathrm{O} / \mathrm{kg} \mathrm{OM} / \mathrm{h}$. The European Commission (Directorate-General Environment ENV A.2) (2001) suggested that OURs lower than $1 \mathrm{~g} \mathrm{O}_{2} / \mathrm{kg} \mathrm{OM} / \mathrm{h}$ can characterize stable composts (Komilis and Tziouvaras, 2009). Whatever the level proposed to validate stability, the proposal for such an indice allows to compare the organic wastes regards to the composting time required to reach the defined threshold. In controlled conditions at laboratory, this time depends mostly on the intrinsic characteristics of the waste. At real scale, it also depends on the composting process i.e. on oxygen supply and air distribution. Thus, in almost all cases, this time should be higher at real scale than in controlled conditions. However, its determination, even in controlled conditions, would help composting operators to adjust their process to the type of waste, especially regarding the aeration strategy and the composting duration. Thus, Komilis (2006) defined this time as "a key parameter for the proper design of solid waste composting facilities". However, few papers compare organic wastes according to the aerobic treatment duration required for their stabilization (Druilhe et al., 2007).

The biodegradability was also considered regarding its influence on the rise of material temperature during composting. Although most of the models of the composting process associate the heat production to the removal of organic matter or to the oxygen consumption rate (Mason, 2006), literature accounts for only two articles (Adani et al., 2006; Scaglia et al., 2000) searching for an experimental quantitative correlation between temperature rise and oxygen consumption during composting. As for time required for stabilization, the rise of material temperature does not depend only on waste nature and properties, but also on the composting process and on the size of the composting cell. However, provide a way to estimate the temperature rise could be helpful to formulate composting mixtures even at real scale.

The analysis of literature emphasizes the need for further work on biodegradability, stabilization kinetics and ability to self-heat during composting. This paper aims to compare household waste, separated pig manure, food waste, pig slaughterhouse sludge and green algae, regarding their biodegradability, the time required for their stabilization and their ability to self-heat during composting. The study consisted in composting experiments under forced aeration. The methods previously mentioned were used to measure wastes biodegradability and to 


\begin{tabular}{|c|c|c|c|}
\hline \multicolumn{4}{|c|}{ Nomenclature } \\
\hline $\mathrm{C}_{\text {bio }}$ & biodegradable carbon & NK & Kjedahl nitrogen \\
\hline COD & chemical oxygen demand & Norg & organic nitrogen \\
\hline $\mathrm{COD}_{\text {bio }}$ & biodegradable fraction of chemical oxygen demand & $\mathrm{NO}_{2}^{-}$ & nitrite \\
\hline $\mathrm{CV}$ & coefficient of variation & $\mathrm{NO}_{3}^{-}$ & nitrate \\
\hline $\mathrm{C} / \mathrm{N}$ & carbon to nitrogen ratio & $\mathrm{OM}$ & organic matter content \\
\hline $\mathrm{DM}$ & dry matter & $\mathrm{OM}_{\text {bio }}$ & biodegradable organic matter \\
\hline $\mathrm{DM}_{\text {bio }}$ & biodegradable dry matter & $\mathrm{OM}_{0}$ & initial content in organic matter \\
\hline $\mathrm{DM}_{0}$ & initial content in dry matter & OUR & oxygen uptake rate \\
\hline DRI & dynamic respiration index & PSS & pig slaughterhouse sludge \\
\hline FW & food waste & SPS & separated pig solids \\
\hline GA & green algae & $\mathrm{TC}$ & total carbon \\
\hline HW & household waste & WC & wood chips \\
\hline $\mathrm{NH}_{4}{ }^{+} / \mathrm{N}$ & 3 total ammoniacal nitrogen & & \\
\hline
\end{tabular}

\section{2. Methods}

\subsection{Composting device}

Three similar reactors were used in parallel for each type of waste. Each reactor (Figure 1) consisted of an airtight stainless steel cylindrical chamber (volume $=300 \mathrm{~L}, \mathrm{H}=80 \mathrm{~cm}, \mathrm{D}=70 \mathrm{~cm}$ ). Heat losses were reduced by insulation provided by a layer of $10 \mathrm{~cm}$ polyurethane. Composting material was placed on a stainless steel grid with $8 \mathrm{~mm}$ square-mesh. Air was blown under the grid and it crossed the composting material. A tap was placed at the bottom of the reactor to collect the leachates. The upper-part of the reactor consisted of a stainlesssteel cone-shaped lid equipped with a gutter allowing condensates collection. The out-going gas passed through a pipe towards a bottle condenser to trap water vapor before reaching gas analyzers and chemical traps. Compost turning required emptying the reactor, mixing and refilling.

The in-coming airflow was adjusted with a flow meter (FL-821-V, OMEGA Engineering Inc.). Taking into account that this adjustment was not accurate enough, a mean value of the flow was calculated every day by dividing the volume of air, which came in the reactor, by the time between two measurements (\#24 hours). The volume of air coming in the reactor for around 24h was measured with a volumetric gas meter (Gallus 2000, 
1 Actaris). Pressure (PTX510, DRUCK), moisture and temperature (dew point and temperature transmitter,

2 VAISALA) of the in-coming air were measured in continue. The measurement of airflow, pressure, moisture 3 and temperature allowed the calculation of the dry-air and the water vapour flows. Dry-air molar flow was presumed nominally constant throughout the system. The temperature of the out-going gas was measured in

5 continue and the out-going water vapour molar flow was calculated by considering the exhaust gas was saturated with vapour. Concentrations of oxygen, carbon dioxide, methane, ammonia and nitrous oxide were measured in both the in-coming and out-going airflows. Oxygen concentration was measured with a paramagnetic analyser (MGA 3000, ADC). Carbon dioxide, methane and nitrous oxide were measured with an IR spectrometric analyser (MGA 3000, ADC). Measurements were given in \% volume for oxygen, carbon dioxide and methane and in ppmv for nitrous oxide. These measurements were performed in continue for 15 minutes per hour on each line $\left(1^{\text {st }}\right.$ reactor, $2^{\text {nd }}$ reactor, $3^{\text {rd }}$ reactor then in-coming air). $\mathrm{NH}_{3}$ was trapped in sulphuric acid $(1 \mathrm{~N})$. The traps $(350 \mathrm{~mL}, 15 \mathrm{~cm}$ height) were changed every day. The composting material temperature was measured continuously thanks to three Pt100 temperature probes located in the low, middle and upper part of the compost. Temperature was measured in the gaseous phase under the lid too. The reactors mass variations were followed in continue, each reactor being placed on a balance constituted by three weight sensors (X201-B, PRECIA MOLEN). Then, the mass of composting material was obtained by subtracting the mass of the reactor. The masses of dry and organic matter were calculated once the experiment was finished by assuming that the removal of organic matter was proportional to oxygen consumption. The condensates and the leachates were collected and weighed every day. Their concentrations in total carbon (TC), chemical oxygen demand (COD), Kjeldahl nitrogen (NK), total ammoniacal nitrogen $\left(\mathrm{NH}_{4}^{+} / \mathrm{NH}_{3}\right)$ and nitrite $\left(\mathrm{NO}_{2}^{-}\right)$and nitrate $\left(\mathrm{NO}_{3}{ }^{-}\right)$were quantified according to the methods described below.

Figure 1 here

\subsection{Organic waste origins}

The household waste (HW) was collected at the plant of Launay-Lantic (Brittany, France) designed to compost 15000 t. HW per year (including 2500 t. industrial biowaste). The waste composition related to dry matter is $18.7 \%$ foodwaste, $16.3 \%$ paper, $6.2 \%$ cardboard, $5.7 \%$ sanitary textiles, $5.9 \%$ plastic films. At this plant, the household waste is introduced in 2 rotating drums $(\mathrm{L}=24 \mathrm{~m}$ length, $\varnothing=3.15 \mathrm{~m})$ where it remains for four days and within it is submitted to forced aeration $\left(1500 \mathrm{~m}^{3} / \mathrm{h} / \mathrm{drum}\right)$. The development of the aerobic biological activity is responsible for an increase of material temperature until $50^{\circ} \mathrm{C}$ whereas moisture decreases from 42 to 

the initial waste and to a decrease of waste size dimensions. Then, the out-going waste is submitted to mechanical treatments in order to extract impurities like metals, plastics and glass. Finally, it is mixed with yard waste, then, composted in windrow for three months. The waste studied was collected after mechanical sorting and before it was mixed with yard waste.

The food waste (FW) was collected at a cafeteria (500 meals/day). FW was composed with both waste produced during meals preparation and food remaining in plates after lunch. This was especially peelings of fruits or vegetables like salad, grapefruit, melon, water melon, pineapple, courgette, cooked potatoes, garden peas, French fries, noodles, rice, cooked meat (pig and chicken) and fish, bread, coffee grounds.

The separated pig solids (SPS) were collected at a pig livestock farm where pig slurry $\left(6156 \mathrm{~m}^{3} / \mathrm{year}\right)$ is centrifuged in order to separate solids from liquid. Then, liquid is treated biologically to remove nitrogen whereas solid fraction (277 t/year), containing most of phosphorus, is composted in order to be exported outside Brittany. Here, SPS was collected after centrifugation and before composting.

The pig slaughterhouse sludge (PSS) was collected at the wastewater treatment plant of the slaughterhouse. The wastewater (1844 $\mathrm{m}^{3} /$ day) was submitted to a primary treatment, which consisted of a flocculation followed by a decantation. Then, the sludge was centrifuged and mixed with lime. In the case of PSS, the experiments at the three aeration rates were not practised simultaneously, i.e. the sludge was sampled between January and October of the same year.

Concern with green algae in Brittany also led us to study their behaviour in composting. The green algae (GA) were collected on the beach of St Michel en Grèves in Brittany. They were rinsed to extract the sand, then, drained for $24 \mathrm{~h}$ before their loading in the composting reactors.

Every waste was collected 24 to $48 \mathrm{~h}$ before they were loaded in the reactors. The amount sampled ranged between 150 and $600 \mathrm{~kg}$ depending on their density and whether they were mixed with wood chips or not. The wastes were stored at $4^{\circ} \mathrm{C}$ until they were loaded in the reactors.

Due to their low porosity, the household waste, the food waste, the pig slaughterhouse sludge and the green algae were mixed with wood chips (WC). The raw wood chips were sieved in two rotating screens. The holes dimensions were respectively $30 \mathrm{~mm}$ and $12.5 \mathrm{~mm}$ diameter, meaning that the wood chips pieces dimensions were comprised between 12.5 and $30 \mathrm{~mm}$. 

were stored inside or outside. Their dry matter (DM) content ranged between 40 and $95 \%$. The wood chips were added to the studied waste on basis of a visual estimation of the physical structure of the mixture. Thus, the mixing ratio on dry masses ratio ranged between 0.3 and $1.1 \mathrm{~kg}$ waste per $\mathrm{kg}$ of wood chips. If necessary, some water was added to the mixtures in order to obtain a moisture content comprised between 55 and $70 \%$. Mixing was carried out in a concrete mixer (150L). Taking into account the densities of the mixtures, for a total volume of around $270 \mathrm{~L}$, the total mass varied from 59 to $196 \mathrm{~kg}$.

Three experiments were performed for each type of waste, each one under a specific aeration rate. After loading, a low aeration flow around $150 \mathrm{~L} / \mathrm{h}$ was applied for 24 to 48 hours until the material temperature increased around $40^{\circ} \mathrm{C}$. Then, the aeration rate was increased and maintained constant. The aeration rates were in the same range for each treatment, comprised between 100 and $1100 \mathrm{~L} / \mathrm{h}$. The value of the highest aeration flow was chosen on basis of airflows applied at real scale. Except for PSS at $105 \mathrm{~L} / \mathrm{h}$ which aimed to limit biodegradation by oxygen supply, the medium and the lowest ones were selected in order to achieve a complete stabilisation i.e. avoid limitation by drying too fast the material. The material was turned once for the separated pig solids, twice for the household waste and the food waste and three times for the green algae. If necessary, some water was added when turning. Composting was stopped when the oxygen consumption rate appeared constant and around zero. The experiments lasted from 27 to 50 days.

Table 1 here

\subsection{Pre-treatments of the waste and the mixtures before chemical characterization}

The methods used for the chemical characterization require a low amount of the studied material. In case of waste with high particles dimensions, the material must be grinded in order both to reduce sampling errors and to allow chemical analyses. With our grinding equipments, waste must usually be dried before grinding. Drying is also responsible for significant losses in total ammoniacal nitrogen and even carbon. Thus, when drying, concentrations in total carbon and total ammoniacal nitrogen in SPS were found as $340.4 \mathrm{~g} \mathrm{TC} / \mathrm{kg} \mathrm{DM}$ and 11.8 g N/kg DM instead of respectively 380.2 and 31.1 when applying analysis on fresh material. Therefore, when possible, an alternative method was used preferentially to one imposing drying. It consisted to apply several aqueous extractions in order to trap volatile material in aqueous extract and prevent its striping through drying. These extractions led to the obtaining of a liquid and a solid phase, both of them being further analyzed separately. The analysis performed on solids and liquids are detailed in the next sub-section (2.5.). Then, the global composition of waste or compost was calculated by adding each contribution (liquid + solid). However, 
although they were lower, this method also led to losses in carbon and nitrogen. Thus, the concentrations in SPS were found as $346.5 \mathrm{~g}$ TC $/ \mathrm{kg} \mathrm{DM}$ and $21.1 \mathrm{~g} \mathrm{~N} / \mathrm{kg}$ DM instead of real ones being respectively 380.2 and 31.1 .

The characterization of the composted mixtures containing wood chips rose other difficulties. At real scale, such a mixture is usually screened to extract compost, which composition depends on screen holes dimensions. Indeed, some parts of the composted waste may remain adsorbed on the bulking agent, whereas this last may be partly removed in the compost. Here, our aim was first to establish some rigorous mass balances. The most usual method consists to dry 1 to $2 \mathrm{~kg}$ of composted mixture, then to grind it and, to analyze the powder. This method may have two limits: the losses when drying before grinding previously mentionned, and sampling errors, especially considering the proportions of waste and wood chips. To avoid these problems, we adopted asstrategy consisting in separating the composted waste from the wood chips as rigorously as possible. This separation was obtained by screening. When the waste was closely stuck on the bulking agent, screening was coupled with an aqueous extraction.

Taking into account that wood chips pieces dimensions were large and that they were mainly constituted of lignin, this method assumed that the wood chips were inert, meaning that their masses in dry matter, total carbon, chemical oxygen demand and nitrogen remained constant during composting. Indeed, de Guardia et al. (2008) showed that wood chips biodegradation during composting accounted for less than $10 \%$ carbon and COD removed from composting mixture and usually less than 5\%. Then, the composted wood chips were not analyzed after composting treatments. Finally, whatever the pretreatment applied to characterize the composted waste, i.e. with or without drying, the same method was used for the pretreatment of the initial waste.

Due to its low dimensions, SPS and SPS composts samples could be analyzed without any drying nor grinding. Although the samples were mixed, the heterogeneity for fresh sub-samples remained higher than if they had been dried and ground. Consequently, whatever the analysis, 5 to 15 measurements were necessary to get a coefficient of variation (CV) lower than $5 \%$.

Fresh green algae were cut in a food grinder. Concerning the final mixtures, the composted green algae were separated from the wood chips thanks to plane sieving in series. These were coupled with manual extraction when wood chips remained adsorbed to green algae. As explained above, the chemical analysis of both fresh GA and composted ones also required 5 to 15 measurements to get a CV lower than $5 \%$.

Mechanical sieving did not allow to separate correctly the composted household waste and the composted pig slaughterhouse sludge from the wood chips in the corresponding composted mixtures. Therefore, HW, PSS and the composted ones were pretreated by applying aqueous extractions. In each case, three samples at the 
minimum were pre-treated then analysed. If the coefficient of variation $(\mathrm{CV})$ was lower than $5 \%$, then the analysis was registered. If not, some additional samples were submitted to pre-treatment and analysis.

For HW and PSS, these extractions were practised by the addition of $1.5 \mathrm{~kg}$ of deionised water to around 500 $\mathrm{g}$ of raw waste. After $20 \mathrm{~min}$ stirring, the waste was screened on a grid with $1 \mathrm{~mm}$ square-mesh. Then, the filtrate was centrifuged at $17700 \mathrm{~g}$ for $10 \mathrm{~min}$ to finish separating the aqueous phase from the solid one. The supernatant was kept apart. The solid phase was added to the solid coarse fraction obtained through screening at $1 \mathrm{~mm}$. The extractions were repeated five times. For every extraction, the amount of water added was twice the amount of solid submitted to extraction. Finally, the five supernatants were gathered and the mixture was filtered on glass micro-fibre filters. The extracted solids were dried and ground. Then, both the solid and liquid samples were analyzed. The results obtained showed that for the household waste, the concentrations in total carbon, chemical oxygen demand and Kjeldahl nitrogen were higher, in the range of respectively 9,16 and $15 \%$, when applying aqueous extractions, than those obtained by drying and grinding.

For composted mixtures, $\mathrm{HW}+\mathrm{WC}$ and PSS $+\mathrm{WC}$, around $3 \mathrm{~kg}$ deionised water was added to $1 \mathrm{~kg}$ composted mixture. After stirring for $20 \mathrm{~min}$, the mixture was screened on a grid with $10 \mathrm{~mm}$ square-mesh to retain wood chips. Then, the aqueous suspension, containing the composted household waste or the composted sludge, was screened on a grid with $1 \mathrm{~mm}$ square-mesh. The filtrate was centrifuged as described above. The supernatant was kept apart and the solid phase was added to the solid coarse fraction obtained by screening at 1 $\mathrm{mm}$. Then, once again, some water was added to the solid phase and after stirring, the screening and the centrifugation were repeated as before. This procedure was repeated five times. Finally, the solid fraction was dried and then ground and analyzed. The supernatants, containing most of the volatile elements, were gathered, then analyzed thanks to the standard chemical methods.

Due to its dimensions and its heterogeneity, the food waste could not be analyzed without any grinding. However, the food grinder was not adapted to it. For sanitary reasons and odors, the aqueous extractions were not applied. Then, in spite of the losses through volatilization, the food waste was dried before grinding and chemical characterization. As for the initial waste, the composted mixture was sampled and the sample was dried and ground before its analysis. Three samples of initial food waste and final composted mixture were analyzed. Since CV were lower than $5 \%$, the characterization was validated.

Taking into account their nature and their dimensions, the fresh wood chips were supposed containing a low amount of volatile elements. Thus, as for food wastes, three samples were dried then ground before characterization. As mentioned earlier, the composted wood chips were not analysed. 


\subsection{Chemical analyses}

Dry matter was measured by drying the initial waste and the composted mixtures (three replicates of about 2 $\mathrm{kg}$ each) at $80^{\circ} \mathrm{C}$, until the weight remained constant. A higher temperature was not used because of the fire hazard with this type of sample. Organic matter $(\mathrm{OM})$ was measured by calcination at $550^{\circ} \mathrm{C}$ of the dried ground samples using the standard method NF U 44-160 (AFNOR, 1985). The aqueous extracts and the solids were characterized through the measurement of their contents in total carbon, chemical oxygen demand, Kjeldahl nitrogen and total ammoniacal nitrogen. The standard methods applied for the liquids were adapted to the solids. In agreement with the method NF-EN-13137 (AFNOR, 2001), the measurement of TC consisted in oxidizing carbon to $\mathrm{CO}_{2}$, then in the measurement of $\mathrm{CO}_{2}$ by infrared spectrometry (SKALAR device for liquids and solids). COD was determined by dichromate oxidation as described in NF T 90-101 (AFNOR, 1971, 2001). $\mathrm{NH}_{4}{ }^{+} / \mathrm{NH}_{3}$ was analyzed by steam distillation using $\mathrm{MgO}$. The distillates were trapped in boric acid $\left(\mathrm{H}_{3} \mathrm{BO}_{3}\right.$, $40 \mathrm{~g} / \mathrm{L})$ and the boric acid distillates were back-titrated using sulphuric acid $\left(\mathrm{H}_{2} \mathrm{SO}_{4}, 0.2 \mathrm{~N}\right)$. NK was quantified by mineralization within a strong acid medium (sulfuric acid 98\%) followed by steam distillation and then titrimetric determination of $\mathrm{NH}_{4}{ }^{+} / \mathrm{NH}_{3}$ as described in the standard NF ISO 11261 (AFNOR, 1995). Organic nitrogen (Norg) was obtained by the subtraction of $\mathrm{N}-\mathrm{NH}_{4}{ }^{+} / \mathrm{NH}_{3}$ from N-NK. Nitrite and nitrate were measured by ionic chromatography (DIONEX DX-120) or by colorimetry thanks to a flow injection analysis (low flow method, Lachat, Quikchem FIA+ 8000 series). The $\mathrm{pH}$ was measured thanks to a $\mathrm{pH}$ meter (Hanna Ph 210) with a probe (pH HI 1131) by dilution of $50 \mathrm{~g}$ wet sample in $500 \mathrm{~mL}$ deionised water.

\section{Results and discussion}

\subsection{Composting materials temperatures}

The composting materials temperatures are represented on Figure 2 as a function of the waste nature and of the aeration rate applied. The rise of temperature during composting can be compared provided the aeration rate is not too low, which may limit the temperature increase, neither too high, which may cool the material. PSS was submitted to the wider range of aeration, from 105 to $1066 \mathrm{~L} / \mathrm{h}$. At the two highest aeration rates, 486 and $1066 \mathrm{~L} / \mathrm{h}$, the material temperature increased, until around $70^{\circ} \mathrm{C}$, and decreased at the same rates (Figure $2 \mathrm{~d}$ ). On the contrary, at $105 \mathrm{~L} / \mathrm{h}$, the temperature increased until a steady state at around $50^{\circ} \mathrm{C}$. It remained stable for 30 days then it decreased at the same rate as the two highest flows. At $105 \mathrm{~L} / \mathrm{h}$, the oxygen supply, $0.04 \mathrm{~mol}$ $\mathrm{O}_{2} / \mathrm{h} / \mathrm{kg} \mathrm{OM}$, was lower than the oxygen demand, around $0.15 \mathrm{~mol} / \mathrm{h} / \mathrm{kg} \mathrm{OM}_{0}$ at $1066 \mathrm{~L} / \mathrm{h}$ (Figure $6 \mathrm{a}$ ) and the temperature profile shows that, in such conditions, the limiting aeration rate allowed to control the material 
temperature. Except for PSS at the lowest flow, oxygen supply was never limiting as shown by Figure 6. Then, the temperature rise can be estimated on the basis of the temperatures registered at the lowest aeration flows, i.e. when heat losses by convection are minimal. Thus, the highest temperatures were observed for PSS, around $70^{\circ} \mathrm{C}$ at $486 \mathrm{~L} / \mathrm{h}$ (Figure 2d), and SPS, around $68^{\circ} \mathrm{C}$ (Figure 2b). GA (Figure 2e) and FW (Figure 2c) exhibited the lowest temperatures, respectively 54 and $47^{\circ} \mathrm{C}$. These results confirm the assumption that the self-heating ability is closely correlated to the waste characteristics. A correlation between the material temperature and its biodegradability will be proposed further (see $\S 3.6$.). Concerning the potential cooling effect of high aeration rates, GA was the most sensible material (Figure 2e). Indeed, the peak of temperature was around $55^{\circ} \mathrm{C}$ at 156 $\mathrm{L} / \mathrm{h}$ whereas it was $41^{\circ} \mathrm{C}$ at $391 \mathrm{~L} / \mathrm{h}$. In contrast, the temperatures of PSS at 486 and $1066 \mathrm{~L} / \mathrm{h}$ (Figure 2d), of SPS (Figure 2b) and of FW (Figure 2c) were almost similar whatever the aeration rate.

Figure 2 here

\subsection{Chemical characteristics of the initial and composted waste}

The chemical characteristics of HW, SPS, FW, PSS, GA and WC are given in Table 2. HW exhibited the lowest moisture content (48.7\%), which difference with FW (70.3\%) is probably due to paper contained in HW. Except for HW, moisture was higher than $67 \%$ and usually comprised between 70 and $77 \%$. The food waste was the most concentrated in organic matter $(91.4 \% \mathrm{DM})$ whereas green algae were the lowest $(53.3 \% \mathrm{DM})$. The concentrations in total carbon and chemical oxygen demand ranged respectively between 260 and $540 \mathrm{~g} / \mathrm{kg} \mathrm{DM}$, and 600 and $1430 \mathrm{~g} \mathrm{O}_{2} / \mathrm{kg}$ DM. However, these variations were mainly due to organic matter content. Indeed, considering all the studied wastes, the mean value of TC was $572.1 \mathrm{~g} / \mathrm{kg} \mathrm{OM}$ with a CV equal to $9.2 \%$. The mean of COD concentrations was $1569.9 \mathrm{~g} \mathrm{O}_{2} / \mathrm{kg} \mathrm{OM}$ with a $\mathrm{CV}$ equal to $18.0 \%$. In contrast, the waste differed significantly to each other regarding their contents in Kjeldahl and total ammoniacal nitrogen. No nitrate neither nitrite were detected in the initial waste.

\section{Table 2 here}

As mentioned before, our purpose was to establish rigorous mass balances rather than characterizing composts, which composition at real scale depends on the screening process. The characteristics of the composted waste are mentioned in Table 3. The results showed that the concentrations in TC and COD usually decreased more or less significantly during composting. The concentrations in $\mathrm{NK}$ and $\mathrm{NH}_{4}{ }^{+} / \mathrm{NH}_{3}$ increased or decreased depending on the waste and on the aeration rate. No nitrate neither nitrite were detected in the composted waste. 


\subsection{Contents in biodegradable matter}

The characterization of the initial and composted waste allowed us to calculate the amounts of DM, OM, TC and COD removed during composting. Moreover, the measurement of the concentrations in oxygen and in carbon dioxide in in-coming and out-going gas flows allowed to calculate the total oxygen consumption and the total carbon dioxide production. The amounts of biodegradable matter removed, expressed as $\mathrm{DM}_{\mathrm{bio}}, \mathrm{OM}_{\mathrm{bio}}, \mathrm{C}_{\mathrm{bio}}$ and $\mathrm{COD}_{\text {bio }}$ or, as $\mathrm{O}_{2}$ consumed and $\mathrm{CO}_{2}$ produced, are given in Table 4 per unit of initial mass of organic matter. These amounts varied only slightly with the aeration rate as confirmed by the values of the coefficients of variation. It should be noted that the characteristics calculated on gases $\left(\mathrm{O}_{2}, \mathrm{CO}_{2}\right)$ vary less than the ones measured on material $\left(\mathrm{DM}_{\text {bio }}, \mathrm{OM}_{\text {bio }}, \mathrm{C}_{\text {bio }}\right.$ and $\left.\mathrm{COD}_{\text {bio }}\right)$, meaning that the sampling and the characterization of solids led to a lower accuracy than the ones on gases. Whatever the indicator, the CV for each waste were always lower than $10 \%$ except for oxygen consumption with the green algae. Probably, the low influence of the aeration rate was due to the low range of aeration flows applied. Thus, the highest CV were observed for PSS, which was submitted to the highest range of aeration rates. Taking into account the low values of $\mathrm{CV}$ and that the experiments were stopped when the oxygen consumption rate became constant and around zero, it can be assumed that the experimental conditions allowed the biodegradation of most of the biodegradable matter which should biodegrade under near optimal conditions of composting. Thus, whatever the limitation, the oxygen supply in case of low aeration rate or, the temperature and the moisture in case of high ones, it did not lead to a significant underestimation of the biodegradable matter assumed to biodegrade during a composting treatment. Then, it was possible to compare the waste regarding their content in biodegradable matter. Taking into account that for each waste the amounts of $\mathrm{CO}_{2}$ produced and of $\mathrm{C}_{\text {bio }}$ are more than twice lower than the amounts of $\mathrm{O}_{2}$ consumed, $\mathrm{DM}_{\text {bio }}$ and $\mathrm{OM}_{\text {bio }}$, and almost three times lower than $\mathrm{COD}_{\text {bio }}$ (Table 4), the amounts of $\mathrm{CO}_{2}$ and $\mathrm{C}_{\text {bio }}$ were multiplied by three, and those of $\mathrm{OM}_{\text {bio }}$ and $\mathrm{DM}_{\text {bio }}$ by two to adjust to the graph type used to compare biodegradability. Thus, Figure 3 shows that there is a rather good correlation between the different indicators i.e. $\mathrm{DM}_{\text {bio }}, \mathrm{OM}_{\text {bio }}, \mathrm{C}_{\text {bio }}$ and $\mathrm{COD}_{\text {bio }}$ on one hand, and $\mathrm{O}_{2}$ consumption and $\mathrm{CO}_{2}$ production on the other. The food waste and the household waste exhibited the highest contents in biodegradable matter, and the separated pig solids and the green algae, the lowest ones. The biodegradability of food waste was around $453 \mathrm{~g} \mathrm{C}-\mathrm{CO}_{2} / \mathrm{kg}$ $\mathrm{DM}_{0}$ whereas Komilis (2006) found it around $364 \mathrm{~g} \mathrm{C}-\mathrm{CO}_{2} / \mathrm{kg} \mathrm{DM}$. The biodegradability of the slaughterhouse sludge (PSS) and of the separated pig solids (SPS) was also measured by respirometry in controlled conditions 
at $40^{\circ} \mathrm{C}$. These biodegradabilities were respectively 1342 and $553 \mathrm{~g} \mathrm{O}_{2} / \mathrm{kg} \mathrm{OM}_{0}$ (Druilhe et al., 2007) i.e.

slightly superior than those measured in composting simulation (1130 and $485 \mathrm{~g} \mathrm{O}_{2} / \mathrm{kg} \mathrm{OM}_{0}$ ).

Figure 4 showed that neither the $\mathrm{C} / \mathrm{N}$ of the waste nor the $\mathrm{C} / \mathrm{N}$ of the mixture (waste + wood chips) allowed to predict the amount of organic matter biodegradable by composting. Indeed, as often mentioned in literature, the chemical contents in carbon and nitrogen may be significantly different from the biodegradable ones. More, as mentioned earlier, considering all the studied wastes, the mean value of TC was $572.1 \mathrm{~g} / \mathrm{kg} \mathrm{OM}$ with a CV equal to $9.2 \%$ and the mean of COD concentrations was $1569.9 \mathrm{~g} \mathrm{O}_{2} / \mathrm{kg} \mathrm{OM}$ with a $\mathrm{CV}$ equal to $18.0 \%$. Then, TC and COD contents expressed per unit mass organic matter were almost similar. In Table 4, data describing biodegradability show that whatever the parameter expressed per unit mass organic matter (TC and COD removed), these differed significantly from one waste to the others. As result, it seems that biodegradability can not be estimated thanks to chemical characteristics of initial materials.

Table 4 here

Figure 3 here

Figure 4 here

\subsection{Kinetics of stabilization}

The kinetics of stabilization of the waste depend on their biochemical composition and on their physical characteristics. However, these kinetics are also influenced by environmental conditions as oxygen supply, temperature or moisture, meaning that they should be measured in controlled conditions. From a practical point of view, one important feature of the kinetics of stabilization is the time for the concentration in biodegradable matter to come down a defined value under optimal composting conditions. This limit can be fixed at different levels according to the compost use. Considering the agronomic use of composts, the determination of a stability level aims to avoid depressive effects on plant growth. At a composting plant, this limit can refer to a low oxygen consumption rate, allowing to place the compost under maturation conditions i.e. a lower aeration and less turning. Finally, this limit can also refer to gaseous pollutants in order to reduce emissions responsible for odours. Thus, D'Imporzano et al. (2008) showed that there is a good correlation between biological compost stability and odour emissions. Whatever the definition of the stability level, literature confirms that such a determination is rather difficult (Barrena Gomez et al., 2006). Here, our purpose has been to compare the studied waste regarding a stability level already used in literature i.e. the Dynamic Respiration Index (DRI), given by Adani et al. (2004) and Scaglia et al. (2000). These last consider that the composts with a DRI lower than $500 \mathrm{mg} \mathrm{O} / \mathrm{h} / \mathrm{kg} \mathrm{OM}$ or $0.016 \mathrm{~mol} \mathrm{O}_{2} / \mathrm{h} / \mathrm{kg} \mathrm{OM}$ can be considered as very stable. The oxygen uptake rates 
1 (OUR) obtained in our study, expressed as function of the initial organic matter contents, $\mathrm{OM}_{0}$, are represented 2 on Figures 5 a, b, c and d for respectively HW, SPS, FW and GA, and on Figure 6a for PSS. On Figure 5, the 3 sudden increases of OUR were due to turning events. Considering the stability level given by Adani et al. (2004) and Scaglia et al. (2000), 20, 25, 25 to 30 and 20-25 days were necessary for respectively HW, SPS, FW and GA to get OUR lower than $0.016 \mathrm{~mol} \mathrm{O}_{2} / \mathrm{h} / \mathrm{kg} \mathrm{OM}$. However, this comparison is a bit inaccurate since the number and the dates of turning differed from one waste to the others. More, as proposed by Adani et al. (2004a) and Scaglia et al. (2000), the DRI should be expressed as function of the instantaneous content in organic matter, $\mathrm{OM}(\mathrm{t})$, and not the initial one. For PSS, material was not turned during composting and Figures $6 \mathrm{a}$ and $6 \mathrm{~b}$ provide a comparison between both OUR expressed as function of $\mathrm{OM}_{0}$ or $\mathrm{OM}(\mathrm{t})$. The instantaneous organic matter content was obtained thanks to the assumption that the organic matter removal was proportional to the oxygen consumption. Once the experiment was finished, the OM content was measured and the total oxygen consumption and the mass of OM removed were calculated. Since the oxygen consumption is followed in continue, the mass of organic matter was obtained by calculation as: $m O M(t)=m O M_{0}-\Delta O M \times\left[O_{2}(0 \rightarrow t)\right] /\left[O_{2}(0 \rightarrow E n d)\right]$, with $\mathrm{mOM}(\mathrm{t})$ and $\mathrm{mOM}_{0}$, the masses of organic matter at $\mathrm{t}$ and initially $(\mathrm{kg}), \Delta \mathrm{OM}$, the mass of organic matter removed during the experiment $(\mathrm{kg})$, $\mathrm{O}_{2}\left(0 \rightarrow\right.$ End), the total consumption of oxygen (moles), and $\mathrm{O}_{2}(0 \rightarrow \mathrm{t})$, the amount of oxygen consumed until the time $\mathrm{t}$ (moles). Whereas OUR expressed as function of $\mathrm{OM}_{0}$ reached the threshold in 21 days, 5 days more were necessary when OUR was given as function of $\mathrm{OM}(\mathrm{t})$. The difference between both values of OUR was all the higher as the amount of the organic matter removed during composting was high. Obviously, the difference is not constant and varies with time since OM content varies with time too. The required duration increased to 25 days for HW and remained similar for SPS and GA. For FW, more than 40 days were necessary for stabilization.

Figure 6a also exhibits the influence of a limiting supply in oxygen on the kinetics of stabilization. In order to illustrate this influence, an OUR profile measured at $220 \mathrm{~L} / \mathrm{h}$ was added to the one at 105,486 and $1066 \mathrm{~L} / \mathrm{h}$. The sludge used at $220 \mathrm{~L} / \mathrm{h}$ was sampled in the same period as the other ones. Whereas the stabilization threshold was reached in 26 days at 1066 and 486 L/h, 35 and 47 days were necessary when the aeration rates were respectively 220 and $105 \mathrm{~L} / \mathrm{h}$. The similar OUR and stabilization duration at 486 and $1066 \mathrm{~L} / \mathrm{h}$ indicated that the increase of the aeration rate from 486 to $1066 \mathrm{~L} / \mathrm{h}$ did not allow to reduce the time necessary for stabilization, meaning oxygen supply was not limiting. In contrast, the increase of time required for stabilization at 105 and $220 \mathrm{~L} / \mathrm{h}$ confirmed oxygen limitation. Indeed, for PSS at 105 and $220 \mathrm{~L} / \mathrm{h}$, the oxygen supply rates 
were respectively 0.040 and $0.081 \mathrm{~mol} / \mathrm{h} / \mathrm{kg} \mathrm{OM}$ whereas the oxygen uptake rates increased until maximums which were respectively 0.040 and around $0.064 \mathrm{~mol} / \mathrm{h} / \mathrm{kg} \mathrm{OM}$ i.e. 99 and $79 \%$ of oxygen provided. The increase of composting duration in case of limiting supply in oxygen could be estimated as follows. The OUR at $105 \mathrm{~L} / \mathrm{h}$ was superposed on the OUR without any oxygen supply limitation i.e. here at $1066 \mathrm{~L} / \mathrm{h}$ (Figure 6c). Then, it was possible to calculate the amount of oxygen $(\mathrm{mol} \mathrm{O} / 2 \mathrm{~kg} \mathrm{OM}$ ) corresponding to the area $\mathrm{A}$ comprised between the limited OUR (at 105 or $220 \mathrm{~L} / \mathrm{h}$ ) and the non-limited OUR (at 486 or $1066 \mathrm{~L} / \mathrm{h}$ ). A was equal to 20.0 and to $8.8 \mathrm{~mol} / \mathrm{kg} \mathrm{OM}_{0}$ at respectively 105 and $220 \mathrm{~L} / \mathrm{h}$. Assuming $\mathrm{A}$ is consumed at the maximum value of limited OUR, the additional delay required for stabilization was calculated by dividing A by this value, i.e. $0.040 \mathrm{~mol} / \mathrm{h} / \mathrm{kg} \mathrm{OM}_{0}$ at $105 \mathrm{~L} / \mathrm{h}$ and $0.064 \mathrm{~mol} / \mathrm{h} / \mathrm{kg} \mathrm{OM}_{0}$ at $220 \mathrm{~L} / \mathrm{h}$. Then, the additional delays for stabilization were estimated to 20.8 and 5.8 days at respectively 105 and $220 \mathrm{~L} / \mathrm{h}$. The experiments showed that the stabilization was delayed of around 21 days at $105 \mathrm{~L} / \mathrm{h}$ and 9 days at $220 \mathrm{~L} / \mathrm{h}$. Taking into account that the sludge was sampled at different dates at the wastewater treatment plant, the difference between experimental and calculated values at $220 \mathrm{~L} / \mathrm{h}$ is acceptable. Then, provided the OUR under controlled conditions, i.e. without oxygen supply limitation, and oxygen supply are known, and that transfer efficiency can be estimated, the method allows a first estimation of stabilization duration in case of limiting aeration.

Finally, the definition of a stability level allows to consider that once this level is reached, the biodegradable matter content can be neglected regarding further evolution through composting. This leads to consider that initial biodegradability is equal to the total amount of oxygen consumed from the beginning of composting until attaining the stability level, and that it is equal to zero when OUR reaches $0.016 \mathrm{~mol} / \mathrm{h} / \mathrm{kg} \mathrm{OM}(\mathrm{t})$. Under this assumption, the decrease of biodegradability corresponds to the amount of oxygen consumed during composting. The decrease of biodegradability is represented on Figure 7 for HW at $117 \mathrm{~L} / \mathrm{h}$, for SPS at $226 \mathrm{~L} / \mathrm{h}$, and for PSS at 105 and $1066 \mathrm{~L} / \mathrm{h}$. The Figure 7 shows that the curve slopes for biodegradability around zero were still high, meaning that the stability threshold might be slightly too high and that the calculated durations were minimal ones. In addition, at real scale, depending on the composting process and especially on oxygen transfer efficiency, this duration should be higher. However, reducing the stability threshold should rather be discussed on basis of potential risks i.e. odours, depressive agronomic effects or aeration needs. Figure 7 also allows to illustrate the potential impact of biodegradability content in case of a reduction of aeration or even its interruption. For example, this impact, in terms of depressive agronomic effects or odours emissions, should be higher with household waste and pig slaughterhouse sludge than with separated pig solids. 


\subsection{Respiratory quotient}

The measurement in continue of oxygen consumption and carbon dioxide production rates allowed calculate the respiratory quotient $\mathrm{CO}_{2} / \mathrm{O}_{2}$. The respiratory quotients, from beginning until stabilization, were comprised between 0.87 and 1.02 which agrees with the values previously found by Nakasaki et al. (1985), Gea et al. (2004) and Komilis and Tziouvaras (2009). Figure 8a gives the variations of $\mathrm{CO}_{2} / \mathrm{O}_{2}$ for household waste, separated pig solids, food waste and pig slaughterhouse sludge during the first ten days of composting. During the first hours, $\mathrm{CO}_{2} / \mathrm{O}_{2}$ increased for SPS and PSS whereas it decreased for $\mathrm{HW}$ and $\mathrm{FW}$. When considering the variations between day one and day two even three, the respiratory quotient decreased whatever the waste. The most significant decrease was observed for HW from 1.72 until 0.82. After ten days, the variations were much lower, without any clear tendency, $\mathrm{CO}_{2} / \mathrm{O}_{2}$ usually varying between 0.8 and 1.0. Whatever the waste, at the end of composting, when reaching stabilisation, $\mathrm{CO}_{2} / \mathrm{O}_{2}$ was around 0.9 . For every waste, the influence of aeration rate was sensible after around ten days composting leading to a discard between $\mathrm{CO}_{2} / \mathrm{O}_{2}$ quotients as illustrated for PSS on Figure 8b. Interpret respiratory quotient variations still remains complex. Indeed, these variations depend on elementary composition of biodegradable fraction but also on parameters ruling accumulation of $\mathrm{CO}_{2}$ in composting material i.e. $\mathrm{pH}$, moisture and aeration rate. Then, stating on stabilization seems easier by considering variations of oxygen uptake rate or/and carbon dioxide production rate rather than ratio $\mathrm{CO}_{2} / \mathrm{O}_{2}$.

\subsection{Amount of biodegradable matter and temperature rise during composting}

The continuous monitoring of the temperatures in the composting material and in the incoming air allowed to determine the mean and the maximum values of temperature rise during composting (Table 4). These correspond to the mean and the maximum values obtained by subtracting the temperature of the incoming air from the material temperature during composting. A correlation was searched between these and the content in biodegradable matter expressed thanks to the oxygen consumption. The temperature rise was shown being all the higher as the mass of biodegradable matter contained in the pilot was high (Figure 9). This mass was calculated as the product of the content in biodegradable matter of the studied waste $\left(\mathrm{g} \mathrm{O}_{2} / \mathrm{kg} \mathrm{OM}_{0}\right)$ by the initial mass of organic matter introduced in the pilot $\left(\mathrm{kg} \mathrm{OM}_{0}\right)$. In case of PSS, applying either a limiting aeration rate $(105 \mathrm{~L} / \mathrm{h})$ or a too high one $(1100 \mathrm{~L} / \mathrm{h})$ was responsible for a lower temperature rise. Except for PSS, in the range of the aeration rates applied, Figure 9 confirms that the aeration rate had a low influence on the rise of material temperature. As a result, the temperature rise depended mostly on waste characteristics i.e. the 
concentration in organic matter per unit volume of pilot and the concentration in biodegradable matter per unit mass of organic matter. However, the influence of the aeration rate was sensible when the ratio of the mass of biodegradable matter to the aeration rate decreased i.e. in case of a low mass of biodegradable matter and at high aeration rates. Thus, for mixtures of green algae with wood chips, when the aeration rates applied were respectively 391 and $721 \mathrm{~L} / \mathrm{h}$, the maximum temperatures were respectively 40,7 and $34,5^{\circ} \mathrm{C}$ versus $53,5^{\circ} \mathrm{C}$ at $156 \mathrm{~L} / \mathrm{h}$. The correlations found between the temperature rise and the mass in biodegradable matter was not possible by considering only the biodegradable organic matter concentration. For example, although GA and SPS had some similar concentrations in biodegradable matter, the lower content in organic matter per unit volume of pilot in the case of GA was responsible for a lower rise of its temperature during composting. Adani et al. (2006) found a good correlation between material temperature and DRI measured in composts. In contrast, Scaglia et al. (2000) failed to predict self-heating thanks to DRI during composting of some municipal solid wastes (MSW), its organic fraction (OFMSW) and some municipal and agro-industrial sludge. Our results are in agreement with the observations of Adani et al. (2006) who explained that the variety of the physical properties of organic waste, in opposition to the homogeneity of composts, did not allow to predict the self-heating of fresh organic waste thanks to the single concentration in biodegradable matter. At real scale, the ratio of heat losses to heat production should be lower and then the heat accumulation higher. This should lead to some higher values of mean and maximum temperature rise. However, the relation found here between temperature rise and the amount of biodegradable matter could be used, at a first step, to optimize the mixture formulation.

\subsection{Carbon and chemical oxygen demand balances}

The characterization of the leachates and the condensates and the following of the oxygen consumption and the carbon dioxide and methane productions allowed us to establish carbon and chemical oxygen demand balance closures (Table 5). Whatever the waste, TC losses in leachates accounted for less than $5 \%$ of carbon removed from material with a mean value at around $0.9 \%$. These losses were higher at low aeration rates than at high ones. COD losses in leachates did not exceed $2.6 \%$ and usually decreased when the aeration rate applied increased. Losses of TC and COD in condensates accounted respectively for less than 1.8 and $0.2 \%$ of the carbon removed from the material.

In most cases, methane emissions accounted for less than $0.5 \%$ carbon removed, meaning that carbon was mainly emitted as carbon dioxide. It was not possible to observe that methane emissions were all the lower as the aeration rate was high. The highest emissions of methane were registered for green algae, between 4.6 and $6.7 \mathrm{~g} \mathrm{C}^{-\mathrm{CH}_{4}}$ per $\mathrm{kg}$ initial mass of organic matter, which could be explained by the physical characteristics of 
1 GA i.e. their aggregation leading to the increase of anaerobic areas in the material. For $\mathrm{GA} \mathrm{CH}_{4} \mathrm{emissions}$ accounted for 2.4 to $3.8 \%$ of the carbon removed. Putting GA at $721 \mathrm{~L} / \mathrm{h}$ aside, $\mathrm{CO}_{2}$ emissions ranged between 79 and $118 \%$ of carbon removed with a mean value around $94 \%$. As a result, the ratio of the total losses of carbon to the amount of carbon removed was comprised between 79 and $123 \%$ and the mean ratio was around $96 \%$.

Similarly, the total oxygen consumption was found to account from 74 to $132 \%$ of the COD removed from material. In our opinion, the emissions of volatile organic compounds do not allow to account for the TC or COD balance defaults. Even then, the losses in TC and the oxygen consumption should not exceed the amounts of TC and COD removed from the materials. Thus, in spite of the precautions taken to sample, pre-treat and characterize the initial substrates and the final mixtures, some experiments did not lead to coherent balances. Although SPS were not mixed with wood chips and although their characterization was practised without any drying, the mass balances obtained with SPS were not more coherent than the other ones. However, our practise let us think that all the sampling, the pre-treatment and the characterization of mixtures containing heterogeneous solids should be further investigated. In the absence of equipment allowing the grinding of high amounts of moistened material, using synthetic packing material facilitating aeration and which can be easily separated after composting, as practised by Komilis (2006), should be favoured.

Gaseous emissions depend on waste nature and on composting conditions and duration. In a review on environmental impacts of biological treatment of organic waste, Mallard et al. (2006) report some ranges of carbon dioxide and methane emissions measured during composting at real scale or in pilots. The emissions of $\mathrm{CO}_{2}$, expressed as $\mathrm{g} \mathrm{CO}_{2} / \mathrm{kg} \mathrm{DM}$, were between 110 and 220 for household waste, between 150 and 750 for animal by-products, around 900 for biowaste and between 580 and 760 for wastewater sludge. In this study, $\mathrm{CO}_{2}$ emissions (in $\mathrm{g} \mathrm{CO}_{2} / \mathrm{kg} \mathrm{DM}$ ) were higher than previous ones i.e. around 940, 460, 1660, 1100 and 440 for respectively household waste, separated pig solids, food waste, pig slaughterhouse sludge and green algae. Mallard et al. (2006) report a wide range of methane emissions i.e. between 0 and $11.9\left(\mathrm{~g} \mathrm{CH}_{4} / \mathrm{kg} \mathrm{DM}\right)$ for animal by-products, and between 0.5 and 9.5 for household waste. The emissions measured here were around 1.3, $0.8,1.8,1.4$ and 3.4 for respectively HW, SPS, FW, PSS and GA. Thus, the variability of methane emissions and their level were much lower which probably results from higher levels of porosity and aeration at laboratory than on most composting plants.

\section{Conclusion}


The study compared household waste, separated pig solids, food waste, pig slaughterhouse sludge and green algae regarding their content in biodegradable matter, their kinetics of stabilization and the levels of emissions in carbon dioxide and methane during their composting. The content in biodegradable matter was given as a function of dry matter, organic matter, total carbon and chemical oxygen demand removed on one hand, and as a function of oxygen consumption and carbon dioxide production on the other. These indicators were found closely correlated whereas $\mathrm{C} / \mathrm{N}$ ratio was found irrelevant to predict biodegradability. The time required for the stabilization of the studied waste was determined in reference to a threshold stability level usually mentioned in literature i.e. OUR lower than $500 \mathrm{mg} \mathrm{O} / \mathrm{h} / \mathrm{kg}$ organic matter. A method was proposed to estimate stabilization delay in case of limiting supply in oxygen at any date of composting. The influence of biodegradability and stabilization kinetics on the potential risks for odours or depressive agronomic effects was illustrated through the representation of the decrease of biodegradability as a function of the duration of composting.

The ability of the wastes to self-heat during composting was shown to be closely correlated to the total amount of biodegradable matter in the composting cell. This correlation allows, at a first approach, to optimise mixtures formulation in order to increase material temperature during composting.

Finally, carbon losses in leachates and condensates were shown to be negligible whereas most of the carbon removed was emitted as carbon dioxide. Mass balances in carbon and chemical oxygen demand were established and carbon dioxide and methane emissions were given for each studied waste. 
This research was funded by the French Agency for Environment and Energy Management (ADEME), the 3 Regional Council of Brittany and the Regional Direction of the Ministry of Agriculture and Forestry (DRAF) of 4 Brittany. The data on green algae were obtained through a study in collaboration with Jean-François Sassi from 5 CEVA (Centre d'Etude et de Valorisation des Algues). 
Adani, F., Confalonieri, R. and Tambone, F., 2004. Dynamic respiration index as a descriptor of the biological stability of organic wastes. Journal of Environmental Quality 33(5): 1866-1876.

Adani, F., Ubbiali, C. and Generini, P., 2006. The determination of biological stability of composts using the Dynamic Respiration Index: The results of experience after two years. Waste Management 26(1): 41-48.

AFNOR, 1971. NF T 90-101 - Détermination de la demande chimique en oxygène (DCO) - Méthode par le dichromate de potassium: $4 \mathrm{p}$.

AFNOR, 1985. NF U 44-160 - Organic soil conditioners and organic material for soil improvment - Determination of total organic matter - Calcination method (Amendements organiques et supports de culture - Détermination de la matière organique totale - Méthode par calcination).

AFNOR, 1995. NF ISO 11261 - Soil quality - Determination of ttotal nitrogen - Modified Kjeldahl method (Qualité du sol Dosage de l'azote total - Méthode de Kjeldahl modifiée): 8 p.

AFNOR, 2001. NF EN 13137 - Characterization of waste - Determination of total organic carbon (TOC) in waste, sludge and sediments (Caractérisation des déchets - Dosage du carbone organique total (COT) dans les déchets, boues et sédiments): $20 \mathrm{p}$.

AFNOR, 2001. NF T 90-101 - Water quality - Determination of chemical oxygen demand (COD) (Détermination de la demande chimique en oxygène $(\mathrm{DCO})): 7 \mathrm{p}$.

Atkinson, C. F., Jones, D. D. and Gauthier, J. J., 1997. Microbial activities during composting of pulp and paper-mill primary solids. Worl Journal of Microbiology and Biotechnology(13): 519-525.

Barrena Gomez, R., Vazquez Lima, F. and Sanchez Ferrer, A., 2006. The use of respiration indices in the composting process: a review. Waste Management \& Research 24(1): 37-47.

Berthe, L., Druilhe, C., Massiani, C., Tremier, A. and de Guardia, A., 2007. Coupling a respirometer and a pycnometer, to study the biodegradability of solid organic wastes during composting. Biosystems Engineering 97(1): 75-88.

D'Imporzano, G., Crivelli, F. and Adani, F., 2008. Biological compost stability influences odor molecules production measured by electronic nose during food-waste high-rate composting. Science of The Total Environment 402(2-3): 278-284.

de Guardia, A., Petiot, C. and Rogeau, D., 2008. Influence of aeration rate and biodegradability fractionation on composting kinetics. Waste Management 28(1): 73-84.

Druilhe, C., De Guardia, A., Berthe, L., Tremier, A. and Martel, J.-L., 2007. Measurement of waste and compost biodegradability by respirometry. Practical applications (Mesure de la biodégradabilité des déchets et des composts par respirométrie. Applications opérationnelles). Techniques, Sciences et Méthodes(5): 44-57.

European Commission (Directorate-General Environment ENV A.2). ( 2001). " Biological treatment of biowaste, working document, 2nd draft." Available from http://www.compost.it/www/pubblicazioni_on_line/bio.pdf.

Gea, T., Barrena, R., Artola, A. and Sanchez, A., 2004. Monitoring the biological activity of the composting process: oxygen uptake rate (OUR), respirometric index (RI) and respirometry quotient (RQ). Biotechnology and Bioengineering (88): 520-527.

Komilis, D. P., 2006. A kinetic analysis of solid waste composting at optimal conditions. Waste Management 26(1): 82-91.

Komilis, D. P. and Tziouvaras, I. S., 2009. A statistical analysis to assess the maturity and stability of six composts. Waste Management 29(5): 1504-1513.

Mallard, P., Rogeau, D., Gabrielle, B., Vignoles, M., Sablayrolles, C., Le Corff, V., Carrere, M., Renou, S., Vial, E., Muller, O., Pierre, N. and Coppin, Y., 2006. Environmental impacts of biological treatments of waste - state of the art (Impacts environnementaux de la gestion biologique des déchets - Etat des connaissance). Ademe Editions: pp 3150.

Mason, I. G., 2006. Mathematical modelling of the composting process: A review. Waste Management 26(1): 3-21.

Nakasaki, K., Shoda, M. and Kubota, H., 1985. Effect of Temperature on Composting of Sewage-Sludge. Applied and Environmental Microbiology 50(6): 1526-1530.

Scaglia, B., Tambone, F., Pier Luigi, G. and Adani, F., 2000. Respiration index determination: Dynamic and static approches. Compots science \& utilization 8(2).

Tremier, A., De Guardia, A., Massiani, C. and Martel, J. L., 2005. Influence of the airflow rate on heat and mass transfers during sewage sludge and bulking agent composting. Environmental Technology 26(10): 1137-1149. 
1 Tremier, A., de Guardia, A., Massiani, C., Paul, E. and Martel, J. L., 2005. A respirometric method for characterising the organic composition and biodegradation kinetics and the temperature influence on the biodegradation kinetics, for a mixture of sludge and bulking agent to be co-composted. Bioresource Technology 96(2): 169-180. 
Table 1

Mixtures composition and composting conditions

\begin{tabular}{|c|c|c|c|c|c|c|c|c|c|c|c|c|c|c|c|}
\hline \multirow[b]{2}{*}{$\begin{array}{c}\text { Fresh mass of HW, SPS, FW, PSS, } \\
\text { GA }(\mathrm{kg})\end{array}$} & \multicolumn{3}{|c|}{ HW + WC } & \multicolumn{3}{|c|}{ SPS } & \multicolumn{3}{|c|}{$\mathbf{F W}+\mathbf{W C}$} & \multicolumn{3}{|c|}{ PSS + WC } & \multicolumn{3}{|c|}{$\mathbf{G A}+\mathbf{W C}$} \\
\hline & 31.62 & 32.02 & 29.91 & 144.03 & 144.74 & 146.39 & 24.51 & 24.31 & 24.73 & 106.49 & 109.63 & 106.23 & 47.48 & 47.50 & 47.50 \\
\hline WC dry matter (\% wet weight) & & 94.5 & & & & & & 57.2 & & 39.9 & 38.8 & 41.8 & & 91.72 & \\
\hline Dry masses ratio $^{\text {a }}$ & 0.52 & 0.55 & 0.56 & & & & 0.35 & 0.35 & 0.36 & 0.71 & 0.82 & 0.78 & 1.04 & 1.05 & 1.03 \\
\hline Water added ${ }^{\mathrm{b}}(\mathrm{kg})$ & 44.11 & 42.07 & 39.13 & & & & 17.00 & 14.81 & 15.64 & & & & & & \\
\hline Total mass (wet weight in $\mathrm{kg}$ ) & 108.96 & 105.47 & 98.26 & 144.03 & 144.74 & 146.39 & 77.50 & 75.38 & 76.52 & 193.36 & 192.68 & 195.52 & 59.79 & 59.79 & 59.94 \\
\hline Initial mixt. moisture (\%) & 56.29 & 56.31 & 56.28 & & 67.49 & & 64.00 & 62.86 & 63.33 & 69.38 & 69.42 & 66.20 & 61.40 & 61.42 & 61.29 \\
\hline Mean aerat ${ }^{\circ}$ flow $(\mathrm{L} / \mathrm{h})$ & 117 & 394 & 746 & 166 & 226 & 443 & 138 & 372 & 773 & 105 & 486 & 1066 & 156 & 391 & 721 \\
\hline $1^{\text {st }}$ turning (day) & 9 & 9 & 9 & 14 & 14 & 14 & 13 & 13 & 13 & & & & 9 & 9 & 9 \\
\hline Water added $^{\mathrm{c}}(\mathrm{kg})$ & 10.06 & 9.78 & 15.01 & & & & & & & & & & & & \\
\hline $2^{\text {nd }}$ turning (day) & 17 & 17 & 17 & & & & 21 & 21 & 21 & & & & 17 & 17 & 17 \\
\hline Water added $^{\mathrm{c}}(\mathbf{k g})$ & & & & & & & 0 & 2.20 & 5.29 & & & & & & \\
\hline $3^{\text {rd }}$ turning (day) & & & & & & & & & & & & & 25 & 25 & 25 \\
\hline Exp. durat $^{\circ}$ (day) & 29 & 29 & 29 & 27 & 27 & 27 & 37 & 37 & 37 & 50 & 29 & 35 & 35 & 35 & 35 \\
\hline Final mass (wet weight in $\mathrm{kg}$ ) & 95.42 & 87.27 & 80.16 & 111.79 & 116.5 & 117.1 & 47.56 & 47.18 & 45.69 & 134.32 & 127.24 & 114.61 & 50.78 & 4898 & 42.05 \\
\hline Final moisture (\% wet weight) & 60.91 & 60.29 & 58.19 & 60.66 & 62.95 & 59.05 & 52.51 & 50.59 & 48.51 & 64.36 & 62.04 & 53.43 & 53.60 & 53.67 & 41.45 \\
\hline
\end{tabular}

${ }^{\mathrm{a}} \mathrm{HW} / \mathrm{WC}, \mathrm{FW} / \mathrm{WC}, \mathrm{PSS} / \mathrm{WC}, \mathrm{GA} / \mathrm{WC}$ in $\mathrm{kg} / \mathrm{kg}$

${ }^{\mathrm{b}}$ no water added initially in case of SPS, PSS, GA

${ }^{c}$ water added when turning 
Table 2

Chemical characteristics of initial wastes and wood chips

\begin{tabular}{|c|c|c|c|c|c|c|c|c|}
\hline & \multirow{2}{*}{ HW } & \multirow{2}{*}{ SPS } & \multirow{2}{*}{ FW } & \multicolumn{3}{|c|}{$\mathbf{P S S}^{\mathbf{a}}$} & \multirow{2}{*}{ GA } & \multirow{2}{*}{$\begin{array}{c}\text { WC } \\
\text { min. - max. }\end{array}$} \\
\hline & & & & $105 \mathrm{~L} / \mathrm{h}$ & 486 & 1066 & & \\
\hline Moisture (\% wet weight) & 48.70 & 67.49 & 70.30 & 76.90 & 76.02 & 72.55 & 75.17 & $5.5-61.2$ \\
\hline OM (\% DM) & 75.8 & 72.2 & 91.4 & 81.5 & 81.4 & 82.9 & 53.3 & $98.0-99.8$ \\
\hline TC (g/kg DM) & 464.2 & 380.2 & 513.1 & 480.3 & 463.2 & 540.6 & 263.4 & $463.3-503.1$ \\
\hline $\mathrm{COD}\left(\mathrm{g} \mathrm{O}_{2} / \mathrm{kg} \mathrm{DM}\right)$ & 1299.2 & 978.8 & 1277.0 & 1429.2 & 1379.4 & 1612.2 & 602.1 & $1274.0-1363.2$ \\
\hline NK (g N/kg DM) & 17.0 & 31.1 & 39.7 & 49.8 & 60.1 & 45.6 & 35.1 & $0.7-1.0$ \\
\hline $\mathrm{NH}_{4}{ }^{+} / \mathrm{NH}_{3}(\mathrm{~g} \mathrm{~N} / \mathrm{kg} \mathrm{DM})$ & 0.0 & 10.5 & $\mathrm{~nm}$ & 6.8 & 9.0 & 12.2 & 0.9 & 0.0 \\
\hline $\mathbf{p H}$ & 8.5 & $\mathrm{~nm}$ & $\mathrm{~nm}$ & 8.7 & 7.3 & 8.0 & 8.1 & $\mathrm{~nm}$ \\
\hline
\end{tabular}

nm: not measured

${ }^{a}$ Since composting experiments with PSS were not performed simultaneously, three samples of PSS were used, each one at a specified aeration rate, leading to three series of characteristics. 
Table 3

Chemical characteristics of the composted wastes

\begin{tabular}{|c|c|c|c|c|c|c|c|c|c|c|c|c|c|c|c|}
\hline & & HW & & & SPS & & & FW & & & PSS & & & GA & \\
\hline Aeration rate $(\mathrm{L} / \mathrm{h})$ & 117 & 394 & 746 & 166 & 226 & 443 & 138 & 372 & 773 & 105 & 486 & 1066 & 156 & 391 & 721 \\
\hline OM $\left(\% \mathbf{D M}^{\mathrm{a}}\right)$ & 87.5 & 86.3 & 86.4 & 62.2 & 62.4 & 62.9 & 97.6 & 96.1 & 96.8 & 69.8 & 67.9 & 73.2 & 20.9 & 24.7 & 20.2 \\
\hline TC $\left(g / \operatorname{kg~DM}^{\text {a }}\right)$ & 443.4 & 498.7 & 487.2 & 323.7 & 315.7 & 314.5 & 457.6 & 444.5 & 444.9 & 391.4 & 393.5 & 440.6 & 145.2 & 162.9 & 150.2 \\
\hline $\operatorname{COD}\left(\mathrm{g} \mathrm{O}_{2} / \mathrm{kg} \mathrm{DM}^{\mathrm{a}}\right)$ & 1149.5 & 1220.8 & 1088.0 & 925.8 & 902.6 & 861.3 & 1229.0 & 1242.0 & 1225.0 & 1062.6 & 113.6 & 1207.7 & 292.0 & 336.9 & 284.9 \\
\hline NK (g N/kg DM $\left.{ }^{\mathrm{a}}\right)$ & 29.6 & 31.8 & 26.0 & 39.5 & 40.5 & 39.1 & 6.2 & 7.6 & 6.7 & 47.6 & 34.9 & 31.8 & 19.3 & 21.7 & 13.7 \\
\hline 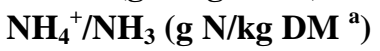 & 0.3 & 0.3 & 0.1 & 10.4 & 9.9 & 10.8 & $\mathrm{~nm}$ & $\mathrm{~nm}$ & $\mathrm{~nm}$ & 18.5 & 9.7 & 5.5 & 4.8 & 4.2 & 2.1 \\
\hline $\mathbf{p H}$ & $\mathrm{nm}$ & $\mathrm{nm}$ & $\mathrm{nm}$ & $\mathrm{nm}$ & $\mathrm{nm}$ & $\mathrm{nm}$ & $\mathrm{nm}$ & $\mathrm{nm}$ & $\mathrm{nm}$ & 8.4 & 7.3 & 7.9 & 8.0 & 7.0 & 8.6 \\
\hline
\end{tabular}

${ }^{\text {a }}$ All the concentrations are given per \% or kg DM of the composted waste and not as function of DM of the final mixture "studied waste + wood chips"

nm: not measured 
Table 4

Removal of biodegradable matter as a function of the waste nature and of the aeration rate

\begin{tabular}{|c|c|c|c|c|c|c|c|c|c|c|c|c|}
\hline & $\begin{array}{l}\text { Aeration } \\
\text { rate }(L / h)\end{array}$ & $\begin{array}{c}\mathrm{g} \mathrm{O}_{2} / \mathbf{k g} \\
\mathrm{OM}_{0}\end{array}$ & $\begin{array}{c}\text { g C- } \\
\mathrm{CO2/kg} \\
\mathrm{OM}_{0} \\
\end{array}$ & $\begin{array}{c}\mathrm{g} \mathrm{C}_{\text {bio }} / \mathrm{kg} \\
\mathrm{OM}_{0}\end{array}$ & $\begin{array}{c}\mathrm{g} \mathrm{COD}_{\text {bio }} / \mathrm{kg} \\
\mathrm{OM}_{0}\end{array}$ & $\begin{array}{c}\mathrm{g} \mathrm{DM_{ \text {bio } }} / \mathrm{kg} \\
\mathrm{OM}_{\mathbf{0}}\end{array}$ & $\begin{array}{c}\mathrm{g} \mathrm{OM}_{\mathrm{bio}} / \mathbf{k g} \\
\mathrm{OM}_{0}\end{array}$ & $\mathbf{C} / \mathbf{N}^{\mathrm{a}}$ & $\begin{array}{c}\mathrm{C} / \mathrm{N} \\
\text { mixt. }^{b}\end{array}$ & $\begin{array}{c}\text { Respiratory } \\
\text { quotient } \\
(\mathrm{mol} / \mathrm{mol}) \\
\end{array}$ & $\begin{array}{c}\mathrm{dT} \\
\text { mean } \\
\left({ }^{\circ} \mathrm{C}\right) \\
\end{array}$ & $\begin{array}{c}\mathrm{dT} \\
\max \\
\left({ }^{\circ} \mathrm{C}\right) \\
\end{array}$ \\
\hline \multirow{5}{*}{ HW } & 117 & 978.8 & 330.9 & 415.4 & 1201.6 & 838.7 & 894.1 & & & 0.90 & 18.9 & 35.6 \\
\hline & 394 & 970.8 & 336.5 & 427.4 & 1265.0 & 918.2 & 978.6 & & & 0.92 & 15.2 & 37.6 \\
\hline & 746 & 954.5 & 348.2 & 380.6 & 1203.2 & 812.5 & 880.7 & & & 0.97 & 14.8 & 37.5 \\
\hline & Mean & 968.0 & 338.5 & 407.8 & 1223.3 & 856.5 & 917.8 & 29.0 & 80.7 & 0.93 & & \\
\hline & $C V(\%)$ & 1.3 & 2.6 & 6.0 & 3.0 & 6.4 & 5.8 & & & 3.9 & & \\
\hline \multirow[t]{5}{*}{ SPS } & 166 & 522.0 & 176.5 & 196.2 & 410.9 & 364.6 & 365.6 & & & 0.90 & 26.5 & 41.5 \\
\hline & 226 & 544.5 & 179.9 & 210.6 & 452.6 & 384.8 & 376.2 & & & 0.88 & 22.6 & 40.5 \\
\hline & 443 & 520.2 & 167.4 & 208.7 & 485.7 & 375.3 & 364.8 & & & 0.86 & 22.1 & 39.2 \\
\hline & Mean & 528.9 & 174.6 & 205.2 & 449.7 & 374.9 & 368.9 & 12.3 & 12.3 & 0.88 & & \\
\hline & $C V(\%)$ & 2.6 & 3.7 & 3.8 & 8.3 & 2.7 & 1.7 & & & 2.5 & & \\
\hline \multirow[t]{5}{*}{ FW } & 138 & 1511.2 & 493.4 & 566.4 & 1220.9 & 797.2 & 775.2 & & & 0.87 & 10.2 & 23.1 \\
\hline & 372 & 1447.0 & 495.7 & 576.1 & 1063.5 & 712.3 & 746.4 & & & 0.91 & 7.4 & 22.1 \\
\hline & 773 & 1362.6 & 498.7 & 551.1 & 1091.5 & 668.1 & 676.9 & & & 0.98 & 7.1 & 22.8 \\
\hline & Mean & 1440.3 & 496.0 & 564.6 & 1125.3 & 725.8 & 732.8 & 12.9 & 46.6 & 0.92 & & \\
\hline & $C V(\%)$ & 5.2 & 0.5 & 2.2 & 7.5 & 9.0 & 6.9 & & & 5.8 & & \\
\hline \multirow[t]{5}{*}{ PSS } & 105 & 1205.0 & 372.9 & 330.3 & 1050.4 & 565.1 & 537.8 & 9.6 & 441.3 & 0.83 & 20.1 & 27.9 \\
\hline & 486 & 1030.0 & 350.9 & 287.7 & 898.3 & 513.1 & 513.5 & 7.7 & 422.8 & 0.91 & 28.5 & 51.0 \\
\hline & 1066 & 1154.4 & 374.2 & 328.3 & 1057.3 & 471.0 & 461.6 & 11.8 & 425.7 & 0.86 & 24.1 & 47.4 \\
\hline & Mean & 1129.8 & 366.0 & 315.4 & 1002.0 & 516.4 & 504.3 & 9.7 & 429.9 & 0.87 & & \\
\hline & $C V(\%)$ & 8.0 & 3.6 & 7.6 & 9.0 & 9.1 & 7.7 & 21.2 & 2.3 & 4.8 & & \\
\hline \multirow[t]{5}{*}{ GA } & 156 & 580.4 & 205.0 & 208.2 & 551.6 & & 590.6 & & & 0.94 & 7.3 & 31.0 \\
\hline & 391 & 536.9 & 220.2 & 197.0 & 510.3 & & 551.7 & & & 1.09 & 5.3 & 18.2 \\
\hline & 721 & 391.8 & 250.0 & 178.2 & 525.3 & & 572.2 & & & 1.70 & 1.9 & 12.0 \\
\hline & Mean & 503.0 & 212.6 & 194.5 & 529.1 & & 194.5 & 7.5 & 374.5 & 1.02 & & \\
\hline & $C V(\%)$ & 19.6 & 5.1 & 7.8 & 4.0 & & 7.8 & & & 10.5 & & \\
\hline
\end{tabular}

${ }^{a} \mathrm{C} / \mathrm{N}$ of HW. SPS. FW. PSS and GA
${ }^{\mathrm{C}} \mathrm{C} / \mathrm{N}$ of mixtures: HW+WC. SPS. FW+WC. PSS+WC and GA+WC 
Table 5

Carbon and COD balances and carbon dioxide and methane emissions

\begin{tabular}{|c|c|c|c|c|c|c|c|c|c|c|c|c|}
\hline \multirow{2}{*}{\multicolumn{2}{|c|}{$\begin{array}{l}\text { Aeration } \\
\text { rate }(\mathrm{L} / \mathrm{h})\end{array}$}} & \multicolumn{5}{|c|}{$\begin{array}{c}\text { Losses in carbon as percent total carbon } \\
\text { removed from material }(\%)\end{array}$} & \multicolumn{2}{|c|}{$\begin{array}{c}\mathrm{CO}_{2} \text { and } \mathrm{CH}_{4} \\
\text { emissions }\end{array}$} & \multicolumn{4}{|c|}{$\begin{array}{l}\text { Losses in COD as percent total } \\
\text { COD removed from material }(\%)\end{array}$} \\
\hline & & \multirow{2}{*}{$\begin{array}{c}\text { Leach. }^{1} \\
0.4\end{array}$} & \multirow{2}{*}{$\begin{array}{c}\text { Cond. }^{2} \\
0.0\end{array}$} & \multirow{2}{*}{$\begin{array}{c}\mathbf{C O}_{2} \\
79.6\end{array}$} & \multirow{2}{*}{$\begin{array}{c}\mathrm{CH}_{4} \\
0.5\end{array}$} & $\begin{array}{l}\text { Closure } \\
\text { in } \\
\text { carbon }^{4}\end{array}$ & \multirow{2}{*}{$\begin{array}{c}\text { g C- } \\
\mathrm{CO}_{2} / \mathbf{k g} \\
\mathbf{O M}_{\mathbf{0}} \\
330.5\end{array}$} & \multirow{2}{*}{$\begin{array}{c}\text { g C- } \\
\mathrm{CH}_{4} / \mathrm{kg} \\
\mathrm{OM}_{0}\end{array}$} & \multirow{2}{*}{$\begin{array}{c}\text { Leach. }^{\mathbf{1}} \\
0.3\end{array}$} & \multirow{2}{*}{$\begin{array}{c}\text { Cond. }^{2} \\
0.0\end{array}$} & \multirow{2}{*}{$\begin{array}{c}\mathbf{O}_{2} \\
81.2\end{array}$} & \multirow{2}{*}{$\begin{array}{c}\begin{array}{c}\text { Closure } \\
\text { in } \\
\text { COD }^{5}\end{array} \\
-18.5\end{array}$} \\
\hline HW & 117 & & & & & -19.50 & & & & & & \\
\hline & 394 & 0.0 & 0.0 & 78.7 & 0.3 & -20.90 & 336.2 & 1.3 & 0.0 & 0.0 & 76.7 & -23.3 \\
\hline & 746 & 0.0 & 0.1 & 91.5 & 0.4 & -8.10 & 347.9 & 1.4 & 0.0 & 0.0 & 79.3 & -20.6 \\
\hline \multirow[t]{3}{*}{ SPS } & 166 & 0.0 & 0.3 & 90.0 & 0.1 & -9.50 & 176.5 & 0.3 & 0.0 & 0.0 & 127.3 & 27.3 \\
\hline & 226 & 0.0 & 0.3 & 85.5 & 0.1 & -14.10 & 179.8 & 0.3 & 0.0 & 0.0 & 120.3 & 20.3 \\
\hline & 443 & 0.0 & 0.3 & 80.2 & 0.2 & -19.30 & 167.3 & 0.4 & 0.0 & 0.0 & 107.1 & 7.1 \\
\hline \multirow[t]{3}{*}{ FW } & 138 & 1.2 & 0.5 & 87.1 & 0.0 & -11.20 & 493.7 & 0.0 & 1.5 & 0.2 & 121.7 & 23.4 \\
\hline & 372 & 1.7 & 0.3 & 86.0 & 0.4 & -11.50 & 496.0 & 2.1 & 2.6 & 0.2 & 132.3 & 35.1 \\
\hline & 773 & 0.7 & 0.4 & 90.5 & 0.5 & -7.80 & 498.7 & 2.9 & 0.2 & 0.2 & 124.3 & 24.7 \\
\hline \multirow[t]{3}{*}{ PSS } & 105 & 5.0 & 0.0 & 112.3 & 1.1 & 18.40 & 372.8 & 3.7 & 1.9 & 0.0 & 114.7 & 16.6 \\
\hline & 486 & 3.2 & 1.8 & 118.3 & 0.0 & 23.30 & 350.7 & 0.1 & 2.2 & 0.1 & 112.2 & 14.4 \\
\hline & 1066 & 1.4 & 0.0 & 104.0 & 0.2 & 5.70 & 374.1 & 0.7 & 0.0 & 0.0 & 101.0 & 1 \\
\hline \multirow[t]{6}{*}{ GA } & 156 & 0.0 & 0.2 & 98.1 & 2.4 & 0.60 & 205.0 & 5.0 & 0.0 & 0.0 & 105.0 & 5 \\
\hline & 391 & 0.0 & 0.2 & 111.7 & 2.3 & 14.10 & 220.3 & 4.6 & 0.0 & 0.0 & 104.9 & 4.9 \\
\hline & 721 & 0.0 & 0.1 & $140.2^{3}$ & 3.8 & 44.03 & 250.0 & 6.7 & 0.0 & 0.0 & 74.4 & -25.6 \\
\hline & Mean & 0.9 & 0.3 & 93.8 & 0.8 & -4.27 & & & 0.6 & 0.0 & 105.5 & 6.12 \\
\hline & Max. & 5.0 & 1.8 & 118.3 & 3.8 & 23.30 & 498.7 & 6.7 & 2.6 & 0.2 & 132.3 & 35.10 \\
\hline & Min. & 0.0 & 0.0 & 78.7 & 0.0 & -20.90 & 167.3 & 0.0 & 0.0 & 0.0 & 74.4 & -25.60 \\
\hline \multicolumn{13}{|c|}{${ }^{1}$ Leachates } \\
\hline \multicolumn{13}{|c|}{${ }^{2}$ Condensates } \\
\hline \multicolumn{13}{|c|}{${ }^{3}$ Not accounted in the calculation of the corresponding mean. minimum and maximum values } \\
\hline \multicolumn{13}{|c|}{ 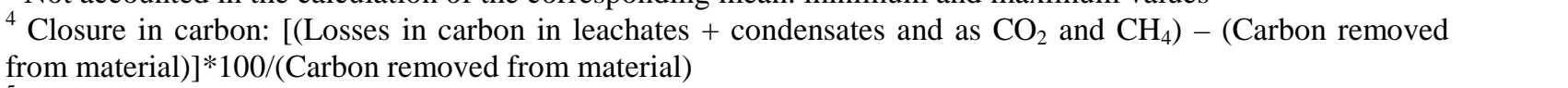 } \\
\hline \multicolumn{13}{|c|}{$\begin{array}{l}{ }^{5} \text { Closure in COD: }\left[\left(\text { total } \mathrm{O}_{2} \text { consumption }\right)-((\mathrm{COD} \text { removed from material })-(\text { Losses in COD in leachates }+\right. \\
\text { condensates }))]^{*} 100 /[(\mathrm{COD} \text { removed from material })-(\text { Losses in COD in leachates }+ \text { condensates })] .\end{array}$} \\
\hline
\end{tabular}




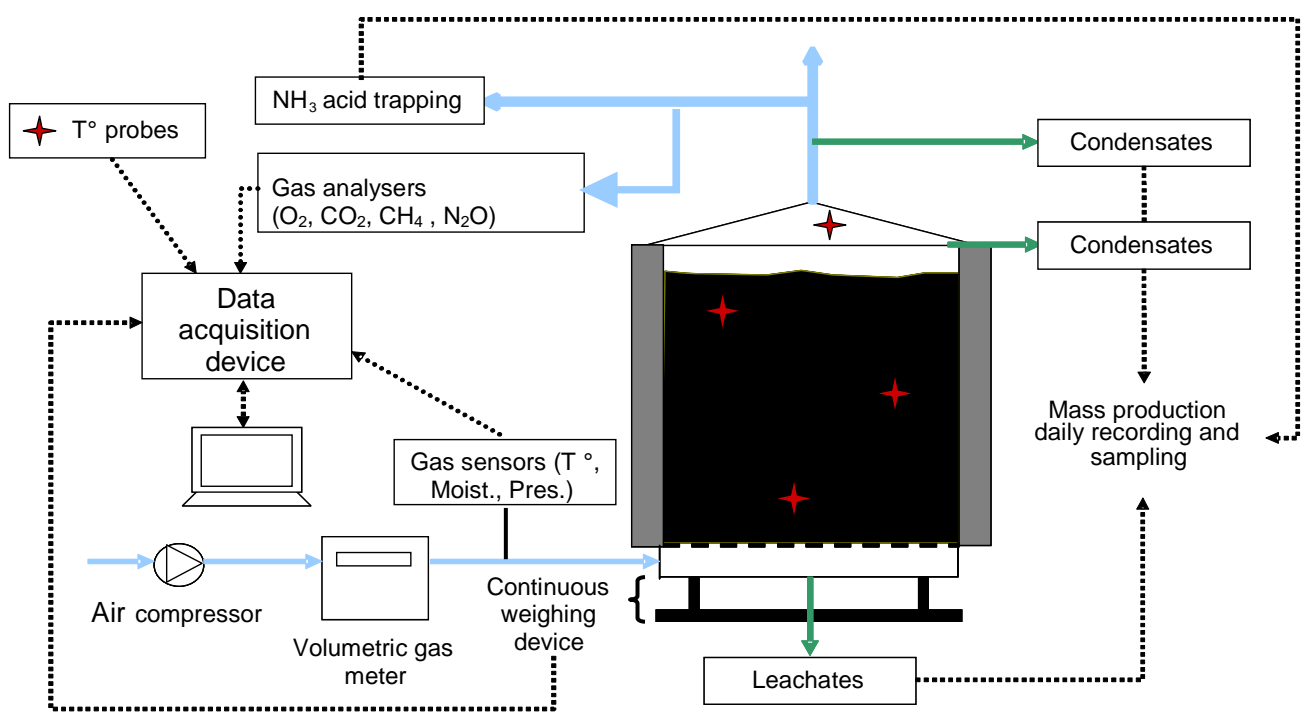

Figure 1: Scheme of the composting simulation reactor and monitoring devices. 

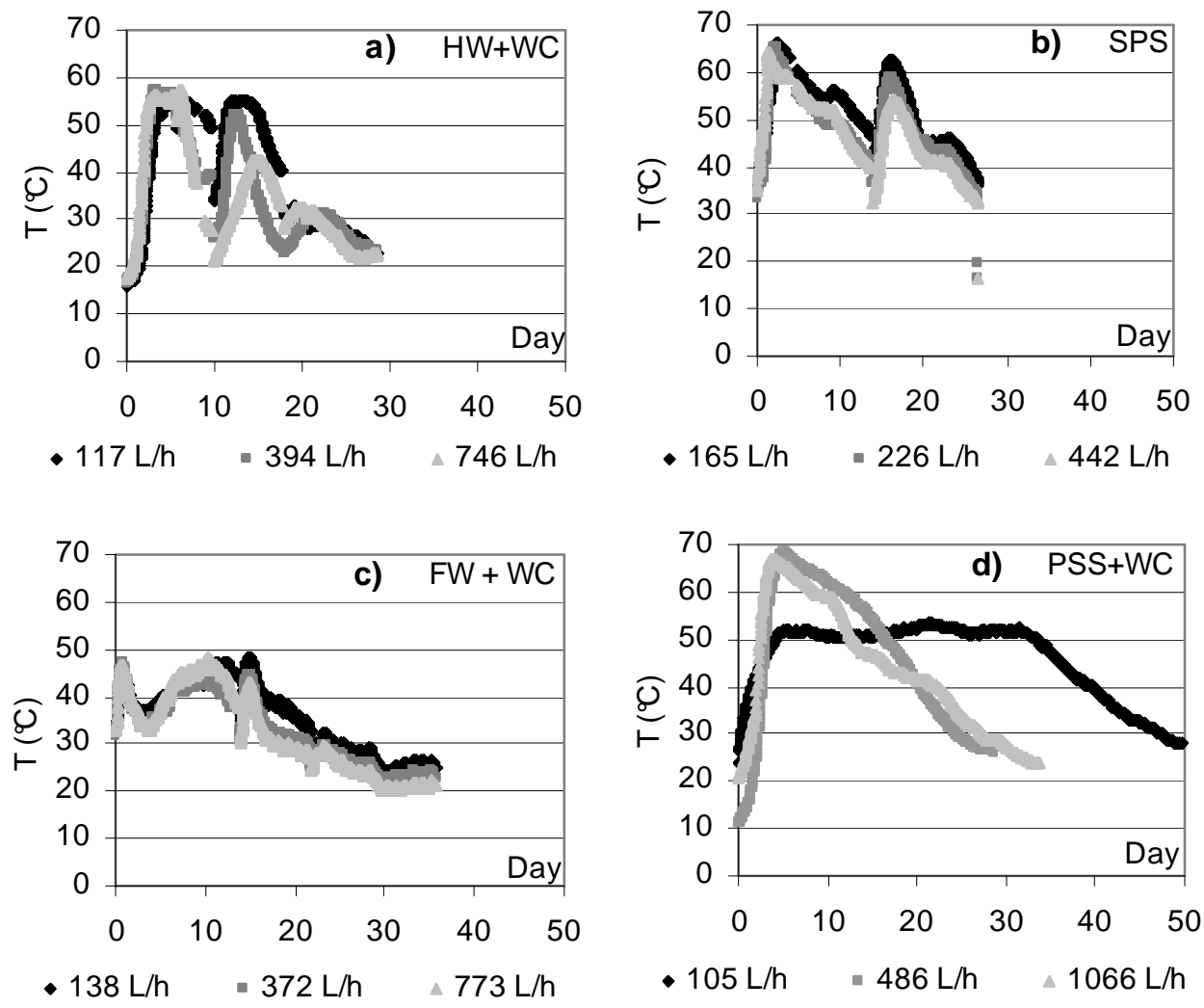

• $138 \mathrm{~L} / \mathrm{h}$ - $372 \mathrm{~L} / \mathrm{h} \quad 4773 \mathrm{~L} / \mathrm{h}$

- $105 \mathrm{~L} / \mathrm{h} \quad-486 \mathrm{~L} / \mathrm{h} \quad \Delta 1066 \mathrm{~L} / \mathrm{h}$

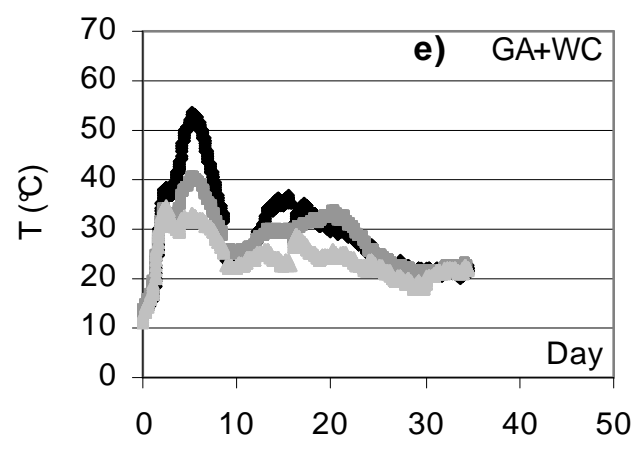

- $156 \mathrm{~L} / \mathrm{h}$ - $391 \mathrm{~L} / \mathrm{h} \quad \Delta 21 \mathrm{~L} / \mathrm{h}$

Figure 2: Composting materials temperatures. 


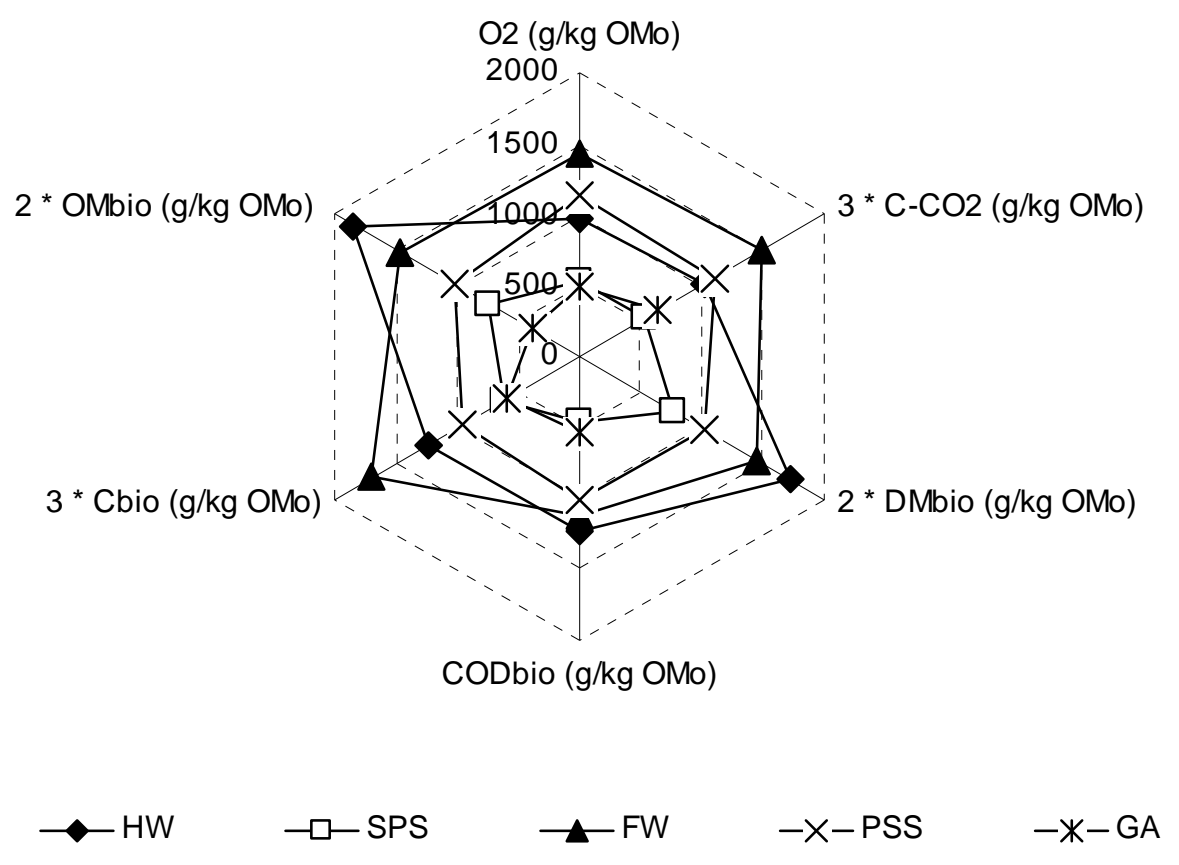

Figure 3: Wastes biodegradability. 


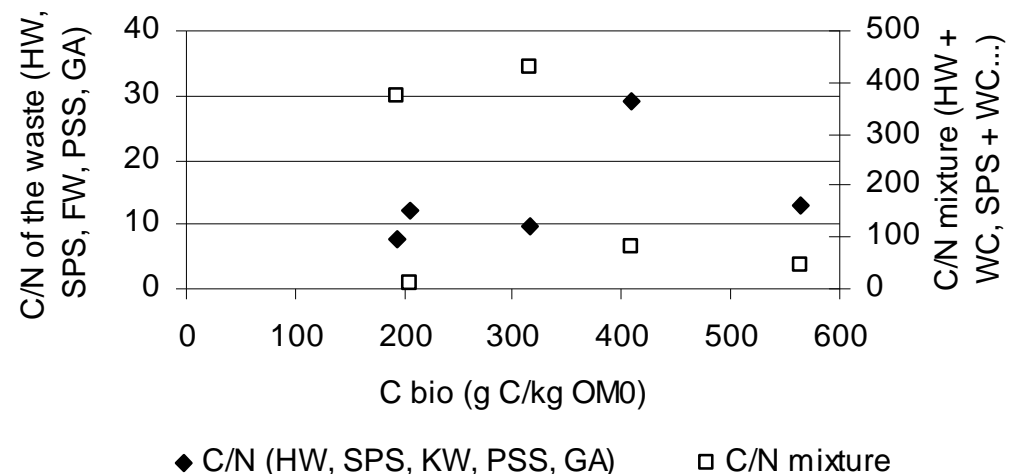

Figure 4: Relevancy of $\mathrm{C} / \mathrm{N}$ as an indicator of biodegradable matter content. 

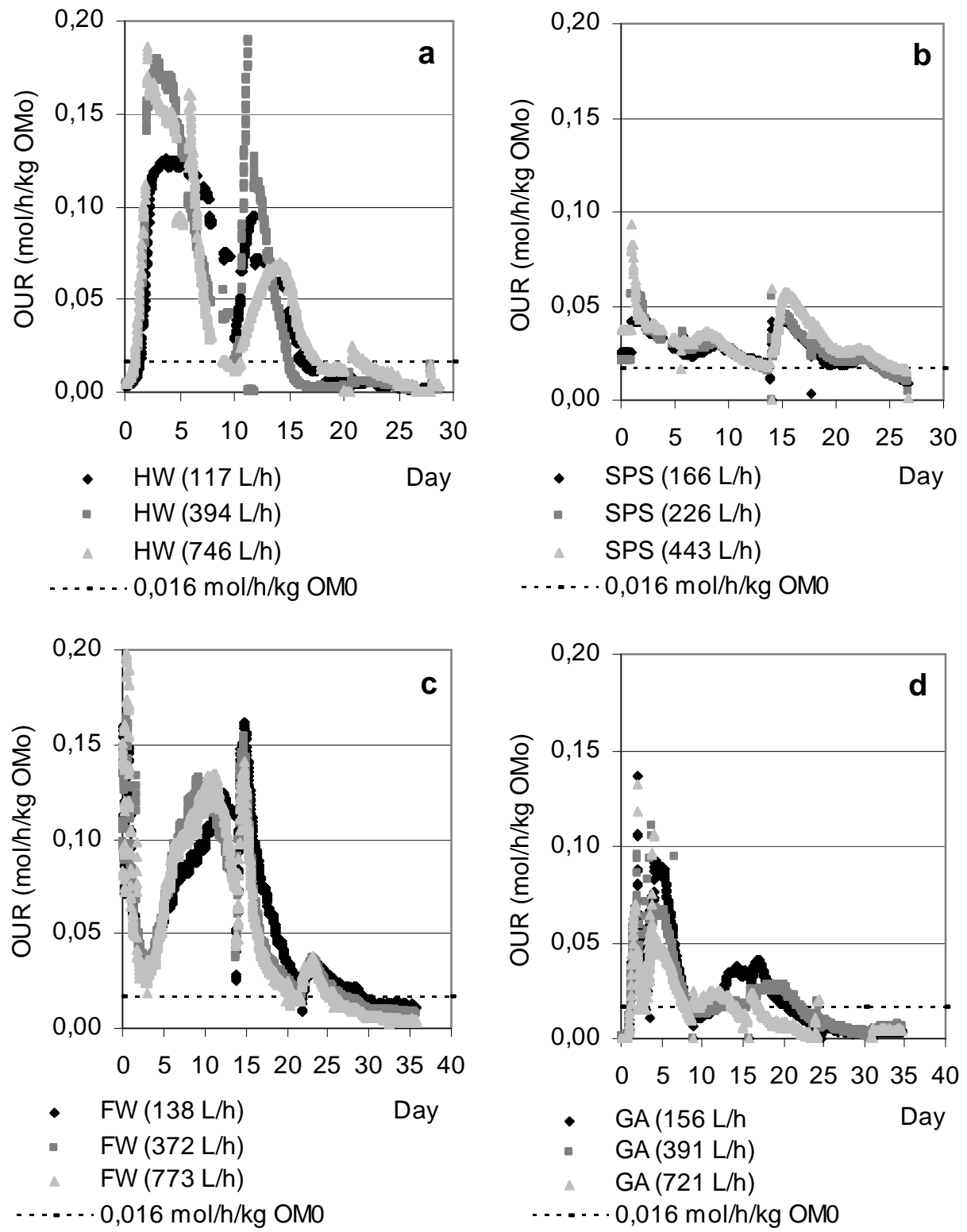

- $\quad \mathrm{FW}(138 \mathrm{~L} / \mathrm{h})$

Day

- $F W(372 \mathrm{~L} / \mathrm{h})$

$\triangle \quad \mathrm{FW}(773 \mathrm{~L} / \mathrm{h})$

$0,016 \mathrm{~mol} / \mathrm{h} / \mathrm{kg}$ OMO

..... 0,016 mol/h/kg OMO

Figure 5: Oxygen uptake rate as a function of the initial content in organic matter. 

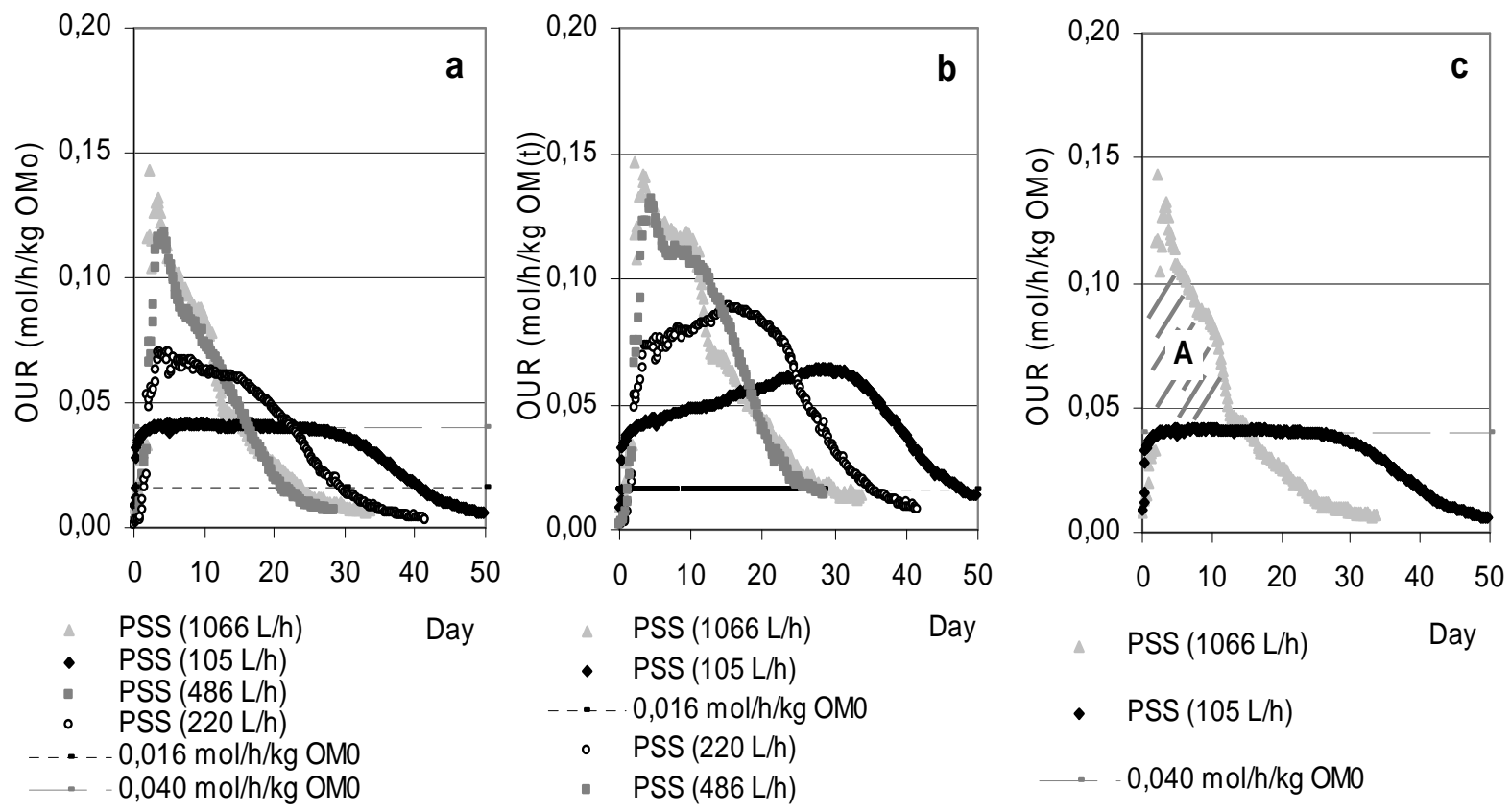

Figure 6: Oxygen uptake rate of PSS as a function of the initial and instantaneous organic matter contents and of the aeration rate. 


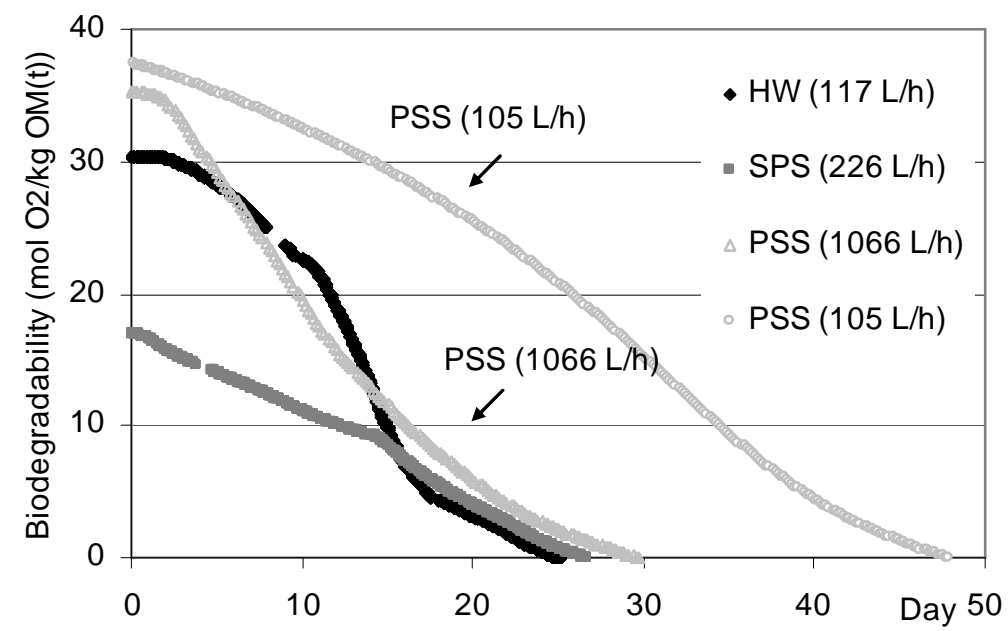

Figure 7: Decrease of biodegradable fraction from beginning until stabilization. 

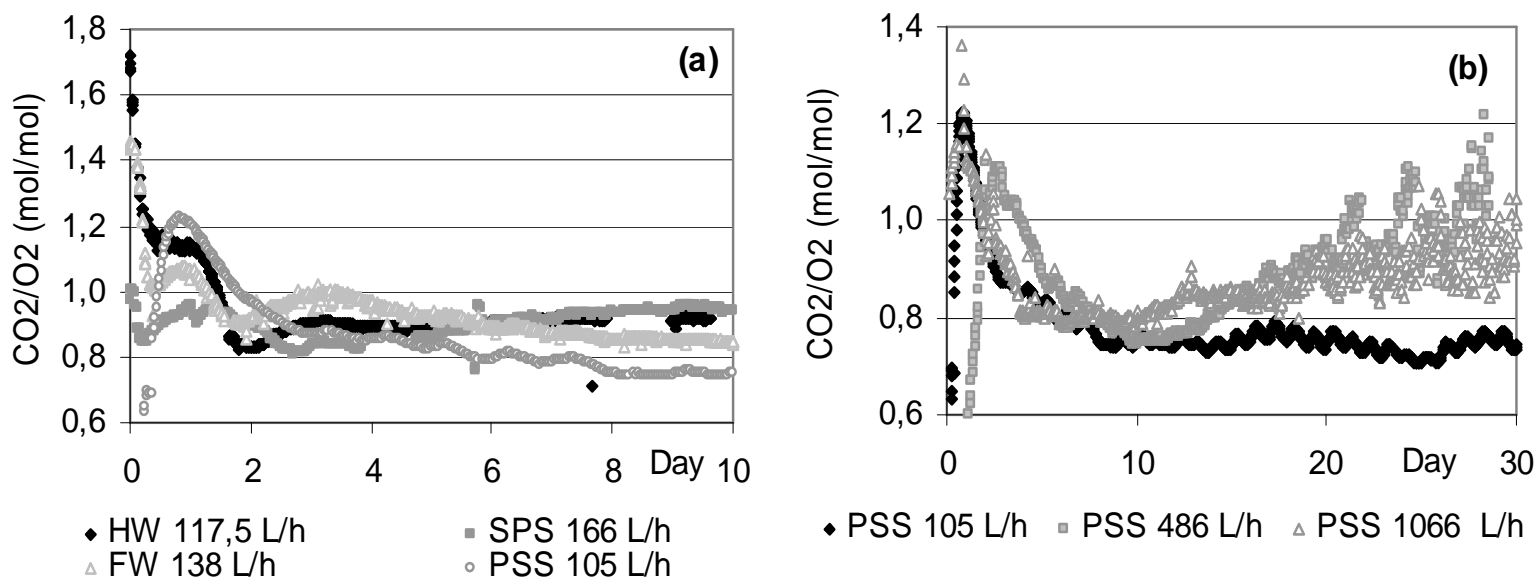

Figure 8: Variations of respiratory quotient for household waste, separated pig solids, food waste and pig slaughterhouse sludge. 


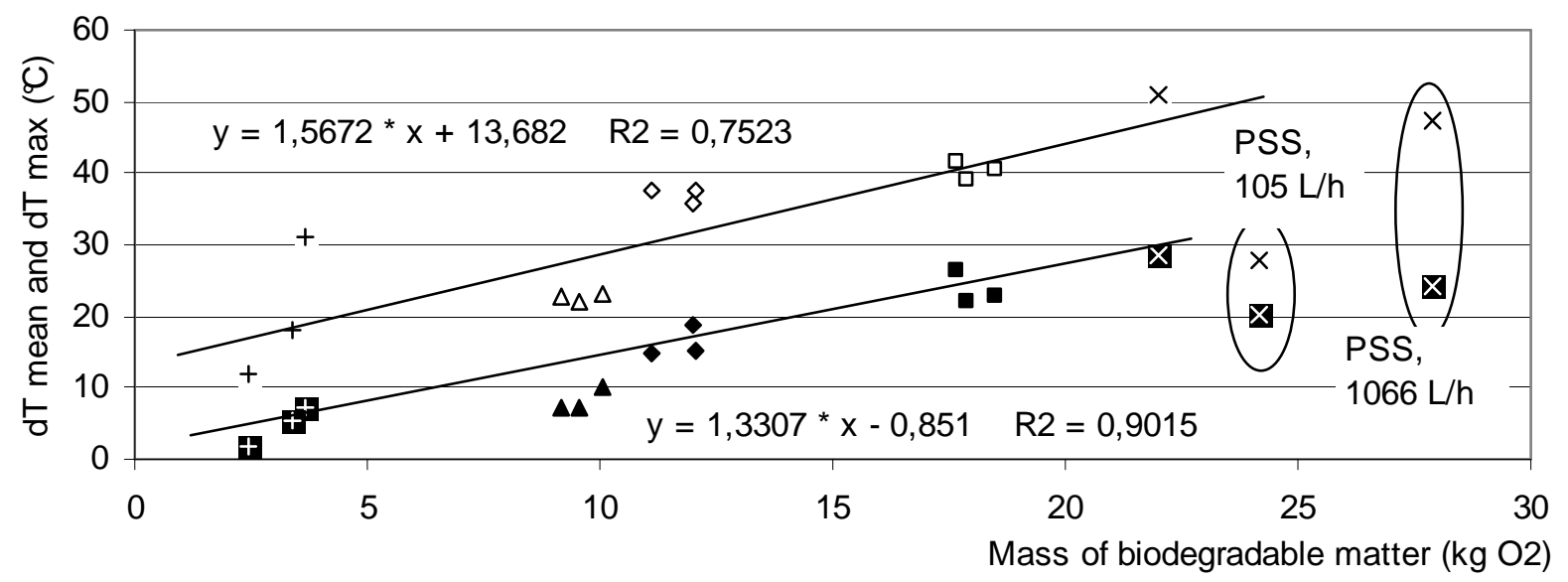

- HW - dT mean a SPS - dT mean $\triangle F W$ - dT mean xPSS - dT mean $\neq$ GA - dT mean $\diamond \mathrm{HW}$ - dT $\max \square \mathrm{SPS}-\mathrm{dT} \max \triangle \mathrm{FW}-\mathrm{dT} \max \times \mathrm{PSS}-\mathrm{dT} \max +\mathrm{GA}$ - dT max

Figure 9: Self-heating as a function of the total mass of biodegradable matter in the pilot. 